\title{
Adaptive Smoothing Power Following Control Strategy Based on an Optimal Efficiency Map for a Hybrid Electric Tracked Vehicle
}

\author{
Baodi Zhang ${ }^{1}$, Sheng Guo ${ }^{1}$, Xin Zhang ${ }^{1, *}$, Qicheng Xue ${ }^{1}$ and Lan Teng ${ }^{2}$ \\ 1 School of Mechanical, Electronic and Control Engineering, Beijing Jiaotong University, Beijing 100044, China; \\ bdzhang@bjtu.edu.cn (B.Z.); shguo@bjtu.edu.cn (S.G.); 17116356@bjtu.edu.cn (Q.X.) \\ 2 School of Economics and Management, Beijing Jiaotong University, Beijing 100044, China; \\ tenglan@bjtu.edu.cn \\ * Correspondence: zhangxin@bjtu.edu.cn; Tel.: +86-10-51688404
}

Received: 18 March 2020; Accepted: 9 April 2020; Published: 13 April 2020

\begin{abstract}
The series hybrid electric powertrain is the main architecture of the hybrid electric tracked vehicle. For a series tracked hybrid electric bulldozer (HEB), frequent fluctuations of the engine working points, deviation of the genset working points from the pre-set target trajectory due to an insufficient response, or interference of the hydraulic pump consumed torque, will all result in increased fuel consumption. To solve the three problems of fuel economy, an adaptive smooth power following (ASPF) control strategy based on an optimal efficiency map is proposed. The strategy combines a fuzzy adaptive filter algorithm with a genset's optimal efficiency, which can adaptively smooth the working points of the genset and search the trajectory for the genset's best efficiency when the hydraulic pump torque is involved. In this study, the proposed strategy was compared on the established HEB hardware in loop (HIL) platform with two other strategies: a power following strategy in a preliminarily practical application (PF1) and a typical power following strategy based on the engine minimum fuel consumption curve (PF2). The results of the comparison show that (1) the proposed approach can significantly reduce the fluctuation and pre-set trajectory deviation of the engine and generator working points; (2) the ASPF strategy achieves a 7.8\% improvement in the equivalent fuel saving ratio (EFSR) over the PF1 strategy, and a 3.4\% better ratio than the PF2 strategy; and (3) the ASPF strategy can be implemented online with a practical controller.
\end{abstract}

Keywords: hybrid electric bulldozer; tracked vehicle; control strategy; adaptive control; power smoothing

\section{Introduction}

In recent years, hybrid electric vehicle (HEV) technology has been rapidly developed. As a new type of power transmission technology, the HEV is recognized as one of the best solutions for energy saving and emission reduction in the world [1]. Following the success of HEV technology in the automotive field [2-4], the world's major manufacturers and related research institutions tried to apply it in the field of construction machinery. In the research and development of hybrid electric construction machinery (HECM), hybrid technology of the loader and excavator has been previously achieved [5,6]. It was not until 2008 that the Caterpillar company developed a diesel-electric driven bulldozer based on HEV technology, named D7E, which attracted extensive attention worldwide due to its excellent performance of $20 \%$ energy saving, $10 \%$ productivity improvement, and $50 \%$ service life extension [7]. After that, a special project was set up to develop the first hybrid electric bulldozer (HEB) of China in 2011 [8]. Since then, research on the HEB, as a heavy-duty off-road hybrid electric tracked vehicle, has received increasing attention [9-11]. 
Control strategies, especially energy management strategies, represent a hot topic in HEV technology research. The core purpose of a control strategy is to optimize the fuel economy and emission of the power system, while satisfying the driving purpose, by reasonably controlling the power distribution among multiple energy sources. The technology of the HECM or hybrid special vehicle should be based on the application, transfer, and expansion of HEV technology. Such control strategies are also research hotspots in their fields. Even with the development and introduction of autonomous vehicles, the vehicle control strategy is the most attractive technical research field [12-14]. HEBs mainly adopt the series hybrid electric powertrain due to their violently fluctuating operating resistance. As the amount of research on the control strategy of series HEB is still small, in order to fully draw lessons from related research results, we have reviewed the control strategy of series HEV, the control strategy of other types of HECMs which also face the problem of HEV technology transfer, and some of the recent research on the HEB control strategy.

Research on the control strategy of the series hybrid power system can be simply divided into three types, based on the characteristics: rule-based control [15], optimization-based control [16,17], and intelligent control $[18,19]$. As shown in Table 1, it can be seen that the three types of control strategies have advantages and challenges in practical engineering applications. The rule-based control strategy is the most commonly used strategy of the series HEV in practical applications. The on-off (thermostat) strategy is the simplest, and permits the genset to always work at the best efficiency point, but the engine is often switched on and off, and the energy loss in start-stop and charge-discharge is large. The power following strategy requires frequent changes in the engine operating points to follow the changing load. However, the engine efficiency is relatively low, the dynamic energy loss is large, and the charge and discharge energy loss of the energy storage unit (ESU) is small [20]. The on-off and power following strategy also are called deterministic rules. The optimization-based control makes use of various optimization algorithms to solve objective functions and obtain the optimal control law. It can be divided to instantaneous and global optimization, according to the time scale of the optimal solution. Two typical instantaneous optimization strategies are the equivalent consumption minimization strategy (ECMS) and its derivative adaptive-ECMS, which calculate the minimum objective function at every moment [16]. Dynamic programming (DP) is a classic and accepted global optimization algorithm used to measure the maximum potential of fuel saving in the whole drive cycle time. Stochastic dynamic programming (SDP) is then formed by considering some uncertainty factors in the load. Between the moment and duration of the optimal time scale, the model predictive control (MPC) converts the solution problem over the entire drive cycle time into a value over a short future period by using sensing devices and methods [21]. An indirect and analytical algorithm employed to solve the global optimal control problem is Pontryagin's minimum principle (PMP), which is also widely adopted and offers an optimal solution close to the DP result by solving a Hamiltonian minimization problem [22]. These optimization-based controls are often segmented into online and offline optimization-based strategies, depending on whether the controls can be applied in real vehicles [1,20]. Fuzzy logic is also mentioned as a kind of rule-based control for fuzzy rules [23], while it is categorized as intelligent control due to its intelligence features of non-model and nonlinear systems in this paper. Intelligent control approaches, including the back propagation neural network (BPNN), genetic algorithm (GA), and machine learning [4,24], which rely on engineering experience and engineering databases, have excellent properties in dealing with uncertain mathematical models, high nonlinearity, and complex task requirements $[25,26]$. They are also widely adopted in series HEVs and have a good adaptability. 
Table 1. Classification and comparison of control strategies of the series hybrid electric powertrain.

\begin{tabular}{cccc}
\hline Category & Subcategory & Advantages & Challenges \\
\hline Rule-Based Control & $\begin{array}{c}\text { On-off } \\
\text { Power following }\end{array}$ & $\begin{array}{c}\text { Simple and reliable, high real-time, widely } \\
\text { used in engineering }\end{array}$ & $\begin{array}{c}\text { Poor portability, poor adaptability, low } \\
\text { energy optimal efficiency }\end{array}$ \\
\hline $\begin{array}{c}\text { Optimization-Based } \\
\text { Control }\end{array}$ & $\begin{array}{c}\text { Instantaneous } \\
\text { optimization } \\
\text { Global } \\
\text { optimization }\end{array}$ & $\begin{array}{c}\text { Accurate optimization objectives and } \\
\text { solutions, instantaneous or global optimal } \\
\text { energy distribution, good fuel economy }\end{array}$ & $\begin{array}{c}\text { Large computation and high requirement } \\
\text { on processor, poor realizability of global } \\
\text { optimization }\end{array}$ \\
\hline Intelligent Control & $\begin{array}{c}\text { Fuzzy logic } \\
\text { Neural network } \\
\text { Expert system }\end{array}$ & $\begin{array}{c}\text { Unnecessary accurate mathematical model, } \\
\text { robust and adaptive, suitable for } \\
\text { real-time control }\end{array}$ & $\begin{array}{c}\text { Depend on the engineering experience or } \\
\text { database, knowledge base highly required }\end{array}$ \\
\hline
\end{tabular}

The control strategies of different types of HECMs have also been studied in terms of the above three aspects. The rule-based control strategies of HECMs have been researched the most. Unlike HEVs, the control strategies of HECMs mainly require the characteristics of operating conditions to be combined. In research on the control strategy of a hybrid excavator, the pressure of the hydraulic pump was often used to identify the working load, and the control rules were made according to the load level [27]. The working process of the excavator and the moving process of each part were analyzed in detail, and the pressure of the operating system was measured in real time to obtain an estimate of the required and recoverable energy [28]. The key point of energy saving control for excavators lies in the design of energy recovery control for moving parts, such as boom and swing systems [29]. Research on the hybrid loader control strategy has also paid attention to the discrimination of operating conditions and to making rules according to the characteristics of the load. The power consumed by a loader's hydraulic system and the impact on the powertrain's dynamic response have often been taken into account to design the strategy [30]. In most studies, the load of the operating system was incorporated into the energy management of the hybrid loader by measuring the outlet pressure of its hydraulic pump [31]. The characteristics of the high transiency and periodicity of construction machinery are both common and specific in control strategy design. The complexity of the working environment of construction machinery, as well as the significant and frequent changes in operating loads, bring new difficulties to energy management and control [6,32]. Research on the HECM control strategy based on an optimization algorithm has been increasing in recent studies. For instance, Nilsson et al. proposed a predictive control approach using SDP under severe disturbances and uncertainties, according to the repetitive pattern of operation of the wheel loaders [33]. SDP control based on prediction also achieved an energy consumption optimization effect on the hybrid excavator [34]. A comparative assessment of ECMS, DP, and thermostat controllers [35]; joint control and parameter optimization by adopting DP control and GA [36]; and a comparison of DP, PMP, and MPC [37], for a hybrid excavator have been conducted. Since intelligent control approaches have a good robustness for nonlinear systems, and HECMs have complex operating conditions and uncertain model parameters, intelligent controls have also been widely studied in this field. Intelligent algorithms such as reinforcement learning [38,39], fuzzy logic [40,41], and the particle swarm optimization (PSO) algorithm [42] have been applied to the energy saving control of HECMs. Therefore, research on other types of HECM control strategies developed according to the characteristics of their operating conditions can provide enlightenment for us to control the HEB: the characteristics of HECMs, such as the periodicity of work, short idle time, and high fluctuation [43], especially the power supply and recovery of the hydraulic actuators, should be taken into account in the control.

At present, only a few institutions have actually developed HEBs, but research articles on control and simulation of the HEB have been increasing in recent years [7,8,44]. In [45,46], the fuel-saving control concept of D7E was briefly introduced; that is, engine control in the series system was not affected by the load torque so that the speed of the generator could be controlled within a narrow range to improve the efficiency, but the detailed control strategy was not given. Song et al. proposed a power following control strategy based on the minimum fuel consumption curve of the engine 
for an HEB [9]. Wang et al. also proposed a load power following control strategy and adopted three engine speed control methods for a comparative study [11]. However, these studies did not take the efficiency of the generator into account when calculating the optimal efficiency. Wang et al. proposed applying MPC to an HEB, compared the MPC to DP and a rule-based control strategy, and artificially added white noise interference to test the robustness of MPC, which indicated that the energy consumption and robustness of the HEB under the MPC strategy are better than those of the rule-based strategy [10,47-49]. Wang et al. then proposed an improved MPC strategy for an HEB without future driving information [50], and applied the MPC to the analysis of the HEB's energy storage unit [51].

Although various types of algorithms have been applied to the control of the HEB in the existing literature, these studies have basically treated the HEB as a tracked vehicle similar to [52,53], which did not pay enough attention to the difference between HEVs and HEBs. Specifically, in most of these HEB control strategies, the influence of the torque consumed by the hydraulic pump of the working system on the genset operating point has not been considered, even though instantaneous disturbance of the hydraulic pump would increase the fuel consumption and emission [45]. In addition, there has been little discussion about the fact that the transient fuel consumption caused by frequent changes of the engine operating points is higher, in which case the load power of the bulldozer fluctuates violently. Additionally, very little attention has been paid to the fact that the frequent adjustment of the HEB's engine operating points causes an insufficient instantaneous response of the engine and then leads to the points deviating from the optimal target trajectory, before finally resulting in an engine efficiency decline. Therefore, it is necessary to carry out in-depth research on these problems for developing the control strategy of HEBs.

Therefore, the purpose of this paper is to propose an innovative Adaptive Smoothing Power Following (ASPF) control strategy to solve the above mentioned problems. In general, the problems include frequent fluctuations of the engine working points, deviation of the genset working points from the pre-set target trajectory due to an insufficient response, and interference of the hydraulic pump consumed torque, all of which result in the fuel consumption increasing. The control strategy takes the impact of the drastic fluctuation in the bulldozer's load and the abrupt demand torque of the hydraulic pump on the working points of the HEB's genset into consideration. The adaptive smoothing algorithm is used to automatically reduce the transient fuel consumption and the working points' deviation from the high efficiency zone. In addition, the algorithm is combined with an optimal efficiency map of the genset considering the correction for interference of the operating system demand torque. A novel transient fuel consumption model embedded in the HEB model and a hardware in loop (HIL) platform is developed to test the proposed approach. The methodology of the proposed control strategy is a combination of fuzzy control theory, real-based control, and the optimization method. The verification method is based on adopting a validated simulation model and an HIL test platform. The test indicates that the proposed approach could solve the above problems and feature an excellent on-line real-time robustness and adaptability for energy saving of the HEB.

The rest of this article is organized as follows: the HEB model with a novel transient fuel consumption model based on BPNN is developed in Section 2; in Section 3, the ASPF based on an optimal efficiency map strategy is proposed and described; the HEB HIL platform is built in Section 4; Section 5 presents the simulation results and a discussion of the proposed approach; and the last section summarizes the major conclusions.

\section{HEB Simulation Model}

A simulation model is the basis for recognizing the characteristics of each part of the HEB and analyzing the control strategy. The control strategy performance can be simulated and analyzed after being incorporated into the simulation model. Additionally, the simulation model is essential and primary for the HIL platform test. Therefore, the simulation model of HEB should first be established. The modeling process is based on an analysis of the HEB architecture and component characteristics. 
The detailed modeling and validation process information can be found in our previous study [54]. The theoretical foundation of the model is derived from the bulldozer's dynamics and kinetics, the component characteristics, and the modeling method of Advanced Vehicle Simulator (ADVISOR) software (Version 2002, National Renewable Energy Laboratory, Golden, CO, USA) [55].

\subsection{HEB Architecture}

The object of this research is derived from the first Chinese HEB - a tracked vehicle that has a series hybrid powertrain and a hydraulic operating system. Its architecture schematic diagram can be seen in Figure 1. This powertrain adopts double wheel-side motors to drive tracks on both sides, enabling the HEB to achieve center-based steering. The drive system employs a typical alternating current(AC)-direct current (DC)-AC transmission form to convert mechanical energy into electrical energy and then mechanical energy. The blade operating system is driven by the hydraulic pump, whose power comes from the engine and flows through the transfer case. Table 2 gives the main specifications of the HEB.

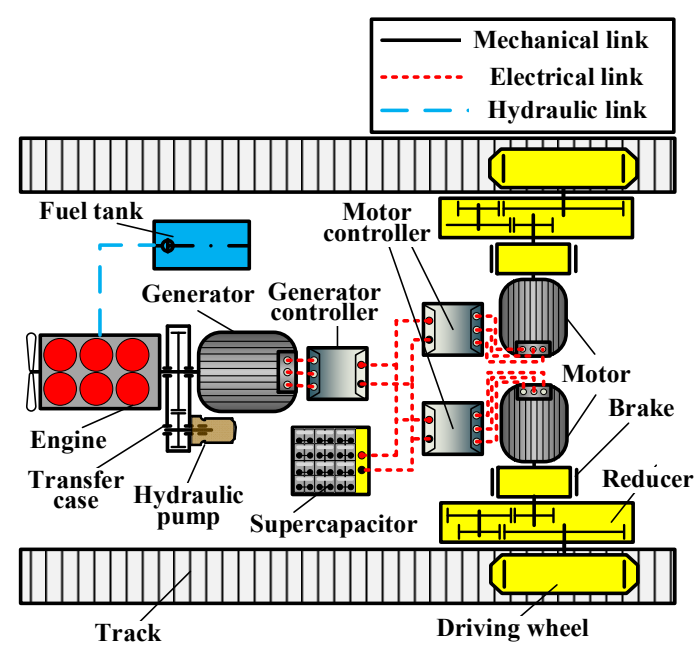

Figure 1. Schematic diagram of the hybrid electric bulldozer (HEB) architecture.

Table 2. Specifications of the HEB.

\begin{tabular}{ccc}
\hline Component & Parameters & Quantity \\
\hline \multirow{2}{*}{ Vehicle } & Curb weight & $27,500 \mathrm{~kg}$ \\
& Dynamic radius & $0.468 \mathrm{~m}$ \\
& Track center distance & $2.000 \mathrm{~m}$ \\
Engine & Track length & $2.730 \mathrm{~m}$ \\
& Rated power & $154 \mathrm{~kW}$ \\
& Rated speed & $1950 \mathrm{rpm}$ \\
& Maximum torque & $927 \mathrm{Nm}$ \\
Generator & Maximum power & $200 \mathrm{~kW}$ \\
& Rated power & $175 \mathrm{~kW}$ \\
& Maximum torque & $1123 \mathrm{Nm}$ \\
& Maximum speed & $2200 \mathrm{rpm}$ \\
Motor & Maximum power & $75 \mathrm{~kW}$ \\
& Rated power & $105 \mathrm{~kW}$ \\
& Maximum torque & $800 \mathrm{Nm}$ \\
Supercapacitor & Maximum speed & $6000 \mathrm{rpm}$ \\
& Static capacity & $5 \mathrm{~F}$ \\
Hydraulic Pump & Energy capacity & $0.34 \mathrm{kWh}$ \\
Reducer & Maximum pressure & $21 \mathrm{MPa}$ \\
& Rated flow & $200 \mathrm{~L} / \mathrm{min}$
\end{tabular}




\subsection{A Novel Engine Model Based on BPNN}

The majority of engine models adopted in HEV simulation research include a kind of simple experimental look-up-table $[9,10,48-53]$, which is acquired from an engine steady-state universal characteristic experiment. This approach can only reflect the static fuel economy, rather than the transient fuel consumption. Therefore, some researchers noticed the difference between steady and transient fuel consumption, began researching transient fuel properties, and attempted to build transient fuel consumption models [56-59]. In [60], it was found that the transient fuel consumption would increase with the increase of the loading rate, as shown in Figure 2.

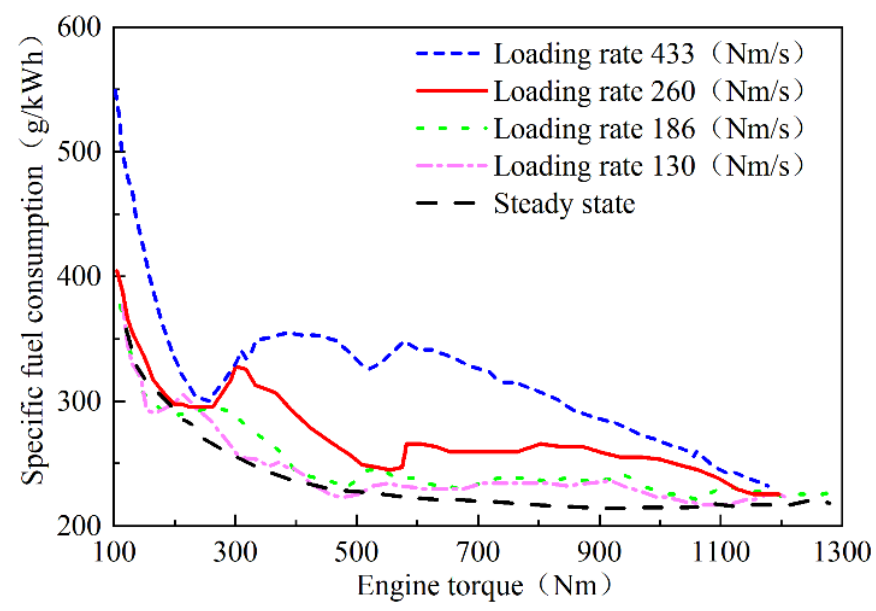

Figure 2. Comparison of the specific fuel consumption of the engine in transient and steady-state conditions. Reproduced from [60], China national knowledge infrastructure, 2015.

Therefore, the increased fuel consumption in a transient state could be more inevitably obvious in the bulldozer's severely fluctuant load. To provide the fuel consumption in this situation with a greater accuracy, a novel engine model with a transient fuel consumption sub-model based on BPNN is proposed in this paper. The modeling approach of key sub-models of the engine model is briefly described in the following.

\subsubsection{Transient Fuel Consumption Model}

The transient fuel consumption model consists of a steady fuel consumption and a transient correction factor. The steady fuel consumption is based on an engine universal characteristic map and calculated by two-dimensional interpolation, which can be shown as

$$
B_{\mathrm{s}}=T_{\mathrm{e}} n_{\mathrm{e}} b e\left(T_{\mathrm{e}}, n_{\mathrm{e}}\right) /\left(9549 \cdot \rho_{\mathrm{fu}}\right),
$$

where $B_{\mathrm{s}}$ is the steady fuel consumption, $T_{\mathrm{e}}$ is the engine torque, $n_{\mathrm{e}}$ is the engine speed, $b e$ is the specific fuel consumption on the basis of the look-up table, and $\rho_{\mathrm{fu}}$ is the fuel density.

The BPNN was selected to identify a transient fuel consumption correction factor due to its excellent learning ability. The engine torque $T_{\mathrm{e}}$, engine speed $n_{\mathrm{e}}$, and their calculated differentials and product were employed as the input layer of the BPNN, considering the engine transient process, including speed and torque variation. The output layer is the correction factor employed to correct the steady fuel consumption model. The BPNN was first trained by a cluster of data collected in the actual engine operation. Figure 3 shows the structure of the transient fuel consumption model based on BPNN. 

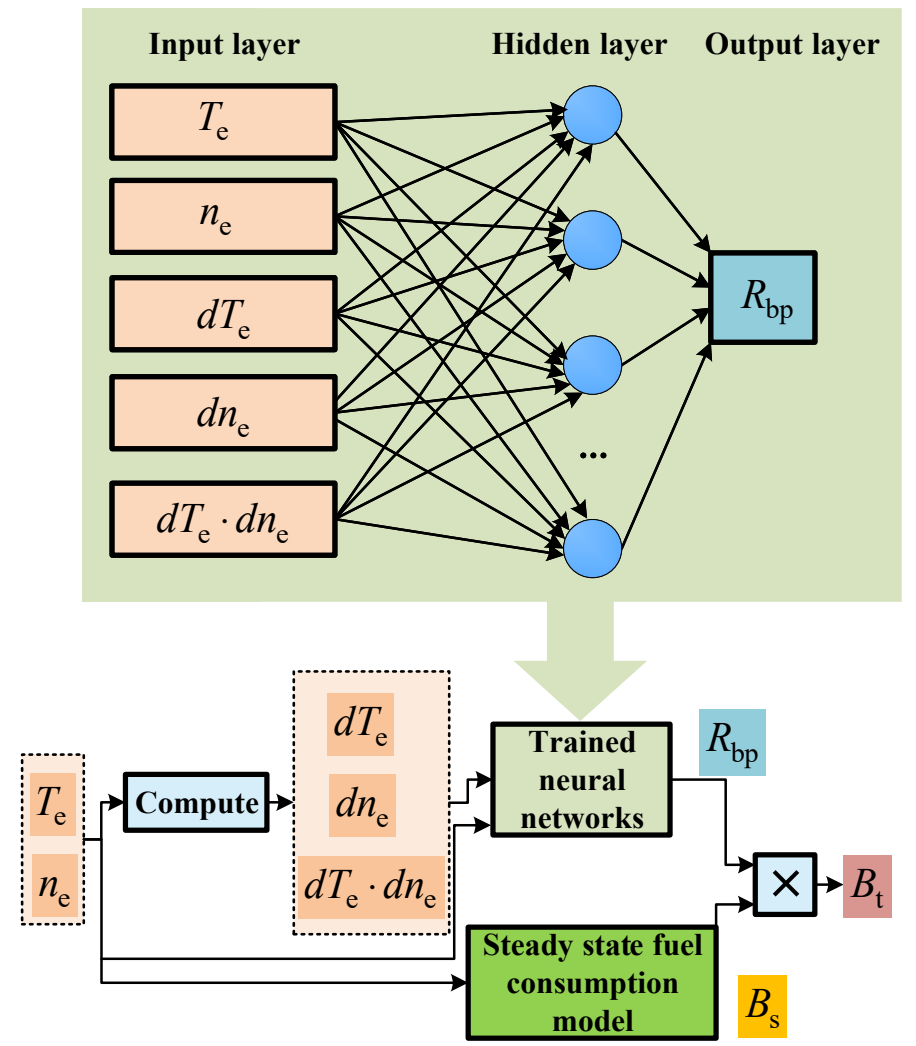

Figure 3. Structure of the transient fuel consumption model based on the back propagation neural network (BPNN).

The transient fuel consumption can be expressed as

$$
B_{\mathrm{t}}=B_{\mathrm{s}}\left(n_{\mathrm{e}}, T_{\mathrm{e}}\right) \times R_{\mathrm{bp}}\left(n_{\mathrm{e}}, T_{\mathrm{e}}, d n_{\mathrm{e}}, d T_{\mathrm{e}}\right),
$$

where $B_{\mathrm{t}}$ is the transient fuel consumption; $R_{\mathrm{bp}}$ is the correction factor based on a trained BPNN calculation; and $d n_{\mathrm{e}}$ and $d T_{\mathrm{e}}$ are the differential of engine speed and torque, respectively.

This BPNN employed the trainlm function as the train function, log-sigmoid as the hidden layer transfer function, and the purelin function as the output layer transfer function. This trained model finally achieved a good simulation performance compared to the experimental data. More details on the model can be found in our previous research [61].

\subsubsection{Output Torque Model}

The steady output torque can be calculated by interpolation of an engine torque-speed-throttle characteristic map as

$$
T_{\mathrm{e}, \mathrm{s}}=f_{\mathrm{Tn}, \mathrm{e}}\left(n_{\mathrm{e}}, \gamma_{\mathrm{e}}\right),
$$

where $T_{\mathrm{e}, \mathrm{s}}$ is the engine steady torque, $f_{\mathrm{Tn}, \mathrm{e}}$ is the interpolation function of the torque-speed-throttle characteristic map, and $\gamma_{\mathrm{e}}$ is the engine throttle.

Considering the transient operation process, a delay of the throttle voltage, injection pressure, and air inflow would lead to a delay of the output torque. For describing the transient process, the dynamic output torque can be expressed as

$$
T_{\mathrm{e}}=T_{\mathrm{e}, \mathrm{s}} \cdot \frac{1}{1+\tau_{\mathrm{e}} \mathrm{s}}
$$


where $T_{\mathrm{e}}$ is the engine dynamic output torque, $\tau_{\mathrm{e}}$ is the engine time constant, and $s$ is the Laplace operator.

\subsection{Driveline Components' Models}

\subsubsection{Electric Machine Model}

The electric machine model is applicable for modeling a motor or generator. The model uses a first-order inertia link to represent the response delay between the output and the target torque. The dynamic output is also limited by the voltage range, maximum current, and external characteristic torque, which can be denoted by

$$
\begin{gathered}
T_{\mathrm{em}}= \begin{cases}\min \left(T_{\mathrm{em}, \mathrm{ul}}, T_{\mathrm{em}, \mathrm{cl}}, T_{\mathrm{em}, \max }\right) & \text { motor mode } \\
\max \left(T_{\mathrm{em}, \mathrm{ul}}, T_{\mathrm{em}, \mathrm{cl}}, T_{\mathrm{em}, \max }\right) & \text { generator mode }\end{cases} \\
T_{\mathrm{em}, \mathrm{ul}}=\left\{\begin{array}{ll}
T_{\mathrm{em}, \mathrm{cmd}} \cdot \frac{1}{1+\tau_{\mathrm{em}} s} & U_{\mathrm{em}, \min } \leq U_{\mathrm{em}}<U_{\mathrm{em}, \max } \\
0 & U_{\mathrm{em}}<U_{\mathrm{em}, \min } \text { or } U_{\mathrm{em}} \geq U_{\mathrm{em}, \max }
\end{array},\right. \\
T_{\mathrm{em}, \mathrm{cl}}= \begin{cases}U_{\mathrm{em}} I_{\mathrm{em}, \max } / \omega_{\mathrm{em}} & \text { motor mode } \\
-U_{\mathrm{em}} I_{\mathrm{em}, \max } / \omega_{\mathrm{em}} & \text { generator mode }\end{cases} \\
T_{\mathrm{em}, \max }= \begin{cases}T_{\mathrm{em}, \max }^{\mathrm{dr}}\left(\omega_{\mathrm{em}}\right) \cdot \frac{1}{1+\tau_{\mathrm{em} s}} & \text { motor mode } \\
T_{\mathrm{em}, \max }^{\mathrm{br}}\left(\omega_{\mathrm{em}}\right) \cdot \frac{1}{1+\tau_{\mathrm{em} s}} & \text { generator mode }\end{cases}
\end{gathered}
$$

where $T_{\mathrm{em}}$ is the output torque of the electric machine; $T_{\mathrm{em}, \mathrm{ul}}, T_{\mathrm{em}, \mathrm{cl}}$, and $T_{\mathrm{em}, \max }$ are the limited torque of the voltage, current, and external characteristic, respectively; $T_{\mathrm{em}, \mathrm{cmd}}$ is the target torque command; $\tau_{\mathrm{em}}$ is the torque respond time constant; $U_{\mathrm{em}}, U_{\mathrm{em}, \min }$, and $U_{\mathrm{em}, \max }$ are the current, minimum, and maximum voltage of the electric machine, respectively; $I_{\mathrm{em} \text {,max }}$ is the maximum current of the electric machine; $\omega_{\mathrm{em}}$ is the angular speed of the machine; and $T_{\mathrm{em}, \max }^{\mathrm{dr}}$ and $T_{\mathrm{em}, \max }^{\mathrm{br}}$ are the maximum permissible limit in the driving or braking process, respectively.

The torque balance equation of the electric machine links the relationship of the torque and the angular speed as follows:

$$
T_{\mathrm{em}}-T_{\mathrm{em}, \mathrm{l}}=J_{\mathrm{em}} \frac{d \omega_{\mathrm{em}}}{d t},
$$

where $T_{\mathrm{em}, l}$ is the load torque and $J_{\mathrm{em}}$ is the rotational inertia of the electric machine.

The efficiency module is the main part of the electric machine model. The efficiency is calculated by a look-up table obtained from an electric machine characteristic experiment, which can be described as

$$
\eta_{\mathrm{em}}=f_{\eta, \mathrm{em}}\left(T_{\mathrm{em}}, n_{\mathrm{em}}\right),
$$

where $\eta_{\mathrm{em}}$ is the electric machine efficiency and $f_{\eta, \mathrm{em}}$ is the interpolation function of the electric machine efficiency map.

Figure 4 provides the efficiency maps of a driving motor and generator. Due to the fact that the electric machine could work in four quadrants as a motor, including the driving and braking state of forward and reverse, the efficiency data of the motor spreads over the four quadrants, while the generator can only operate in one quadrant to generate power.

\subsubsection{Supercapacitor Model}

The supercapacitor model was developed as an equivalent circuit model. The model takes the impact of temperature into account. The resistance and capacitor are the functions of the temperature and current, and described as

$$
R e_{\mathrm{sc}}=f_{\mathrm{Re}, \mathrm{sc}}\left(\operatorname{Tem}_{\mathrm{sc}} I_{\mathrm{sc}}\right),
$$




$$
C_{\mathrm{sc}}=f_{\mathrm{C}, \mathrm{sc}}\left(\operatorname{Tem}_{\mathrm{sc}}, I_{\mathrm{sc}}\right) \text {, }
$$

where $R e_{\mathrm{sc}}$ is the resistance of the supercapacitor, $T e m_{\mathrm{sc}}$ is the temperature, $I_{\mathrm{sc}}$ is the current, $C_{\mathrm{sc}}$ is the capacitor, $f_{\mathrm{Re}, \mathrm{sc}}$ represents the resistance function, and $f_{\mathrm{C}, \mathrm{sc}}$ represents the capacitor function.

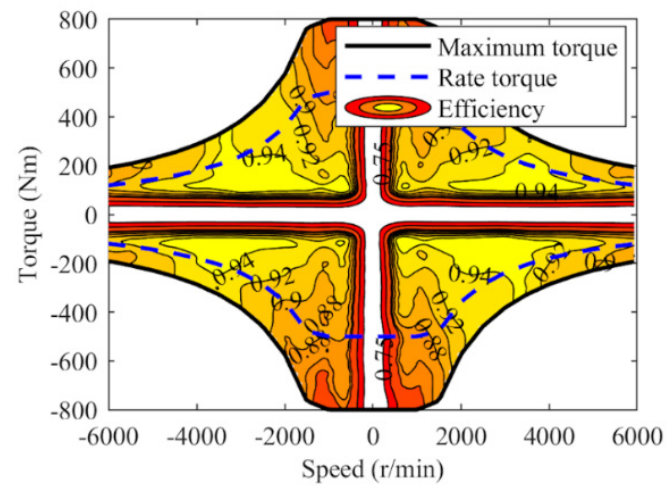

(a)

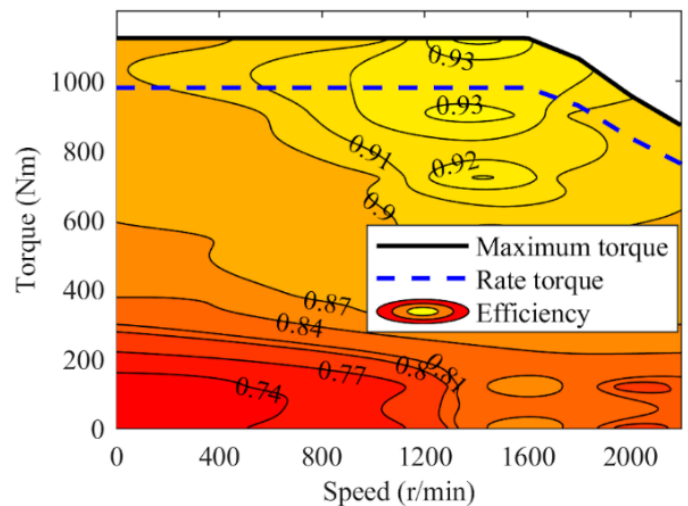

(b)

Figure 4. Efficiency map of a (a) driving motor and (b) generator.

The parameters of the circuit part can be calculated as

$$
\begin{gathered}
I_{\mathrm{sc}}=\frac{U_{\mathrm{sc}}-\sqrt{\left(U_{\mathrm{sc}}^{2}-4 R e_{\mathrm{sc}} P_{\mathrm{sc}}\right)}}{2 R e_{\mathrm{sc}}}, \\
U_{\mathrm{sc}}(n+1)=U_{\mathrm{sc}}(n)-I_{\mathrm{sc}} d t / C_{\mathrm{sc}}, \\
S O C=\left(U_{\mathrm{sc}}(n+1)-U_{\mathrm{sc}, \min }\right) /\left(U_{\mathrm{sc}, \max }-U_{\mathrm{sc}, \min }\right),
\end{gathered}
$$

where $U_{\mathrm{sc}}$ is the voltage, and $U_{\mathrm{sc}, \min }$ and $U_{\mathrm{sc}, \max }$ are the minimum and maximum voltage of the supercapacitor, respectively.

The temperature of the supercapacitor is calculated according to the power loss of resistance and coulombic efficiency and heat transfer process. The temperature can be shown as

$$
\begin{gathered}
\operatorname{Tem}_{\mathrm{sc}}=T e m_{\mathrm{sc}, \mathrm{ini}}+\int_{0}^{t} \frac{P_{\mathrm{sc}, \mathrm{h}}-P_{\mathrm{sc}, \mathrm{a}}}{m_{\mathrm{sc}} \mathcal{s c}_{\mathrm{sc}}} d t, \\
P_{\mathrm{sc}, \mathrm{h}}= \begin{cases}I_{\mathrm{sc}}^{2} R e_{\mathrm{sc}}^{\mathrm{dis}} & I_{\mathrm{sc}} \geq 0 \\
I_{\mathrm{sc}}^{2} R e_{\mathrm{sc}}^{\mathrm{chg}}-I_{\mathrm{sc}} U_{\mathrm{sc}}\left(1-\eta_{\mathrm{coul}}\right) & I_{\mathrm{sc}}<0^{\prime}\end{cases} \\
P_{\mathrm{sc}, \mathrm{a}}=\left(T e m_{\mathrm{sc}}-T e m_{\mathrm{a}}\right) / R e_{\mathrm{h},}
\end{gathered}
$$

where $T e m_{\mathrm{sc}}$ is the supercapacitor temperature; $\mathrm{Tem}_{\mathrm{sc}, \mathrm{ini}}$ is the initial temperature of the supercapacitor; $\mathrm{Tem}_{\mathrm{a}}$ is the ambient air temperature; $P_{\mathrm{sc}, \mathrm{h}}$ is the heat power; $P_{\mathrm{sc}, \mathrm{a}}$ is the heat power transferred to air; $m_{\mathrm{sc}}$ is the mass; $c_{\mathrm{sc}}$ is the specific heat capacity; $R e_{\mathrm{sc}}^{\mathrm{dis}}$ and $R e_{\mathrm{sc}}^{\mathrm{chg}}$ are discharge and charge resistance, respectively; $\eta_{\text {coul }}$ is the coulombic efficiency; and $R e_{\mathrm{h}}$ is the heat resistance.

\subsubsection{Hydraulic Pump Model}

The hydraulic pump model mainly presents its torque and power consumption and simplifies the hydraulic operation system, which is sufficient for researching the powertrain energy and control. The hydraulic pump model can be denoted by 


$$
\begin{gathered}
T_{\mathrm{hp}}=\frac{p_{\mathrm{hp}} q_{\mathrm{hp}}}{2 \pi \eta_{\mathrm{hp}}}, \\
P_{\mathrm{hp}}=\frac{50 p_{\mathrm{hp}} Q_{\mathrm{hp}}}{3 \eta_{\mathrm{hp}}}, \\
Q_{\mathrm{hp}}=\frac{q_{\mathrm{hp}} n_{\mathrm{hp}}}{1000},
\end{gathered}
$$

where $T_{\mathrm{hp}}$ is the torque of the hydraulic pump, $n_{\mathrm{hp}}$ is its speed, $p_{\mathrm{hp}}$ is the outlet pressure, $q_{\mathrm{hp}}$ is its displacement, $\eta_{\mathrm{hp}}$ is its efficiency, $P_{\mathrm{hp}}$ is its power consumption, and $Q_{\mathrm{hp}}$ is the flow.

\subsubsection{Tracked Walking Mechanism Model}

The tracked walking mechanism model is represented based on the kinematic relationship and takes the slip ratio as a major factor into consideration. The traction and speed of the tracks can be formulated as

$$
\begin{gathered}
F_{\mathrm{t}}=\frac{T_{\mathrm{t}}^{\mathrm{in}} \eta_{\mathrm{t}}}{r_{\mathrm{dw}}}, \\
\omega_{\mathrm{t}}=\frac{v}{(1-\varphi) r_{\mathrm{dw}}},
\end{gathered}
$$

where $F_{\mathrm{t}}$ is the tangential traction of tracks, $T_{\mathrm{t}}^{\text {in }}$ is the input torque, $\eta_{\mathrm{t}}$ is the track efficiency, $r_{\mathrm{dw}}$ is the radius of the driving wheel, and $\varphi$ is the track slip rate.

\subsection{Dynamic Model}

The HEB has to overcome the resistance of bulldozing, climbing, ground deformation, acceleration, and air friction. The air friction is small and can be neglected due to the velocity of the bulldozer being very low. The dynamic model can be shown as

$$
F_{\mathrm{t}}=m_{\mathrm{veh}} g \mu \cos \alpha+m_{\mathrm{veh}} g \sin \alpha+\xi m_{\mathrm{veh}} \frac{d v}{d t}+F_{\mathrm{b}}
$$

where $m_{\mathrm{veh}}$ is the HEB mass, $g$ is the gravitational acceleration, $\alpha$ is the slope angle, $\xi$ is the rotary mass coefficient, $v$ is the velocity, $\mu$ is the ground deformation resistance coefficient, and $F_{\mathrm{b}}$ is the bulldozing resistance.

In order to accurately calculate the resistance, the $\xi$ was identified and the $F_{\mathrm{b}}$ was extracted in our previous research [7].

Finally, the HEB model was built in the Simulink environment, as shown in Figure 5.

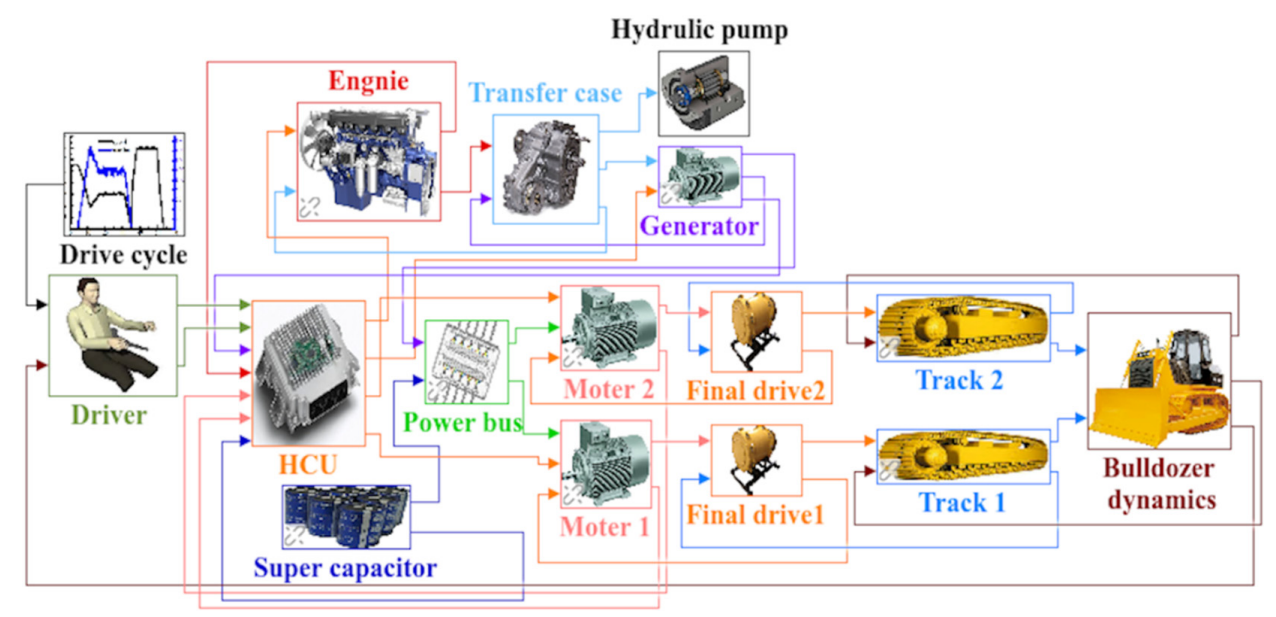

Figure 5. HEB model in Matlab/Simulink. 


\section{ASPF Control Strategy}

The control strategy is the core of this paper and plays an important role in every performance of the HEB. It was developed and optimized according to three current problems that we found in existing research. Therefore, the target problems are presented below, firstly by simulating the operation and control process. The methodology of the control strategy is based on fuzzy control theory, a filter algorithm, optimization, and a rule-based strategy. The detailed structure and composition of the proposed control strategy is then introduced.

\subsection{Target Problem}

The control improvement goal of this research is to resolve three problems. The first two problems are related to the limitation of genset's output power and the fluctuation of working points. The last is related to re-establishing the working points on the optimal efficiency trajectory according to the involvement of the interference torque.

\subsubsection{Frequent Fluctuation of Genset's Working Points}

In most studied power following control strategies, the genset output power is conducted to follow the drive system demand power. As the demand power is constantly changing, the operation points of the genset also frequently change. In particular, when the operation points are controlled on a pre-set trajectory, different powers correspond to different speeds and torques, resulting in severe fluctuations of the speed and torque of the genset and further leading to an increase of transient fuel consumption.

\subsubsection{Large Change Rate of Output Power}

A large change rate of the genset output power will cause its operation points to deviate from the target pre-set trajectory. Due to rapid change of the transient drive system demand power, and switching operation points requiring a certain response time, the points may deviate from the trajectory in the switching process. This deviation will cause the operation points to depart from the minimum fuel consumption curve and spread over a lower efficiency district, resulting in a deterioration of fuel consumption.

The transition processes of different change rates of output power were simulated to illustrate the process, as shown in Figure 6. It indicates that the actual working points deviate from the pre-set minimum fuel consumption curve because of the rapid power change and insufficient responsiveness. However, this phenomenon disappears and the points track the trajectory well if the power change is slow.

\subsubsection{Hydraulic Pump's Interference in Target Trajectory}

The torque consumed by the hydraulic pump will also lead to the genset operation points deviating from the pre-set target trajectory for torque interference. Most previous studies have ignored the hydraulic pump torque and its interference effect [8-10,50,51], which will finally cause a decrease of the genset efficiency and increase of fuel consumption.

\subsection{Development of the ASPF Strategy}

An ASPF control strategy is proposed here to provide a comprehensive solution to these problems. Through this strategy, the demand power signal is divided into the trend part and the fluctuation part to make the genset output smooth and stable, and the supercapacitor supply the output power fluctuation. Therefore, the transient fuel consumption and the deviation from the target trajectory can be reduced. Meanwhile, when there is torque consumption of the hydraulic pump in the working system, the optimal efficiency working points of the genset are found for control to avoid interference. The structure and development process are presented below. 


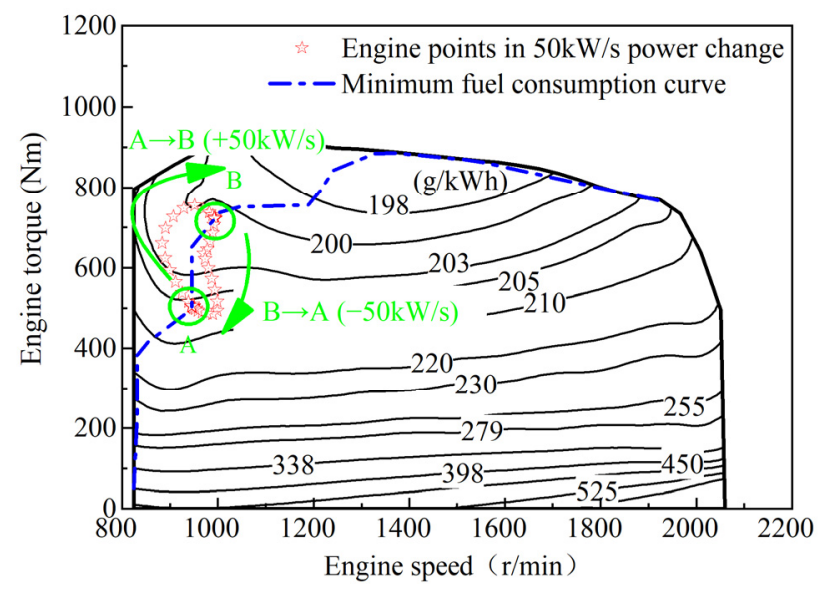

(a)

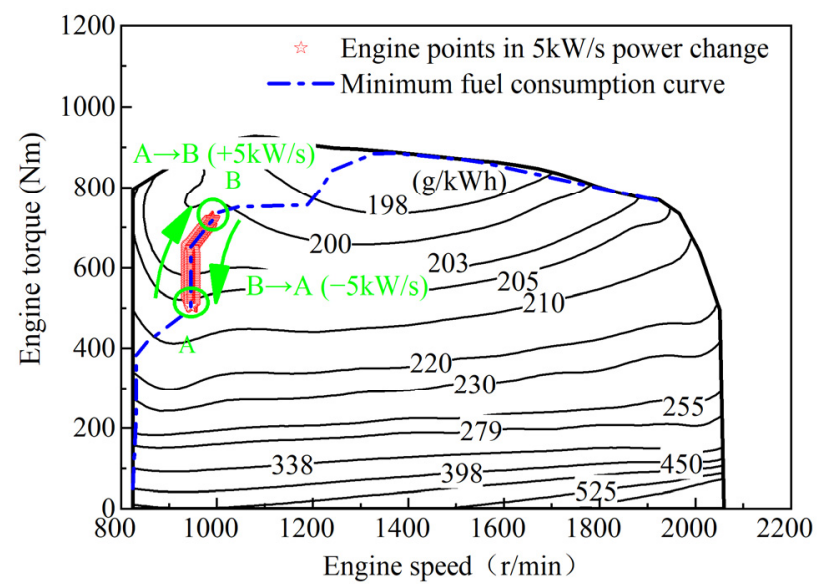

(b)

Figure 6. Effect of different changes of the genset's output power on the engine operating points: (a) 50 and (b) $5 \mathrm{~kW} / \mathrm{s}$ power change.

\subsubsection{Structure of the ASPF Strategy}

The structure of proposed ASPF control strategy is shown as Figure 7. It employs two critical steps, including a fuzzy adaptive filter and optimal efficiency control of the genset module, to solve the problems above and improve the power following control strategy. Utilizing the computed demand power of the drive system as the input, and introducing state of charge (SOC) and pressure feedback, the strategy outputs the engine target speed and generator target torque to the subcomponent controller. Energy distribution between the genset and the supercapacitor can be completed through determining the genset output power.

\subsubsection{Fuzzy Adaptive Filter}

The fuzzy adaptive filter integrates a fuzzy logic controller with a first-order inertia filter. By using the self-adaptability of the fuzzy controller to automatically adjust the filter coefficient, the output power can be smoothed with the SOC in a permissive range. Figure 8 shows the smoothing process based on the fuzzy adaptive filter. 


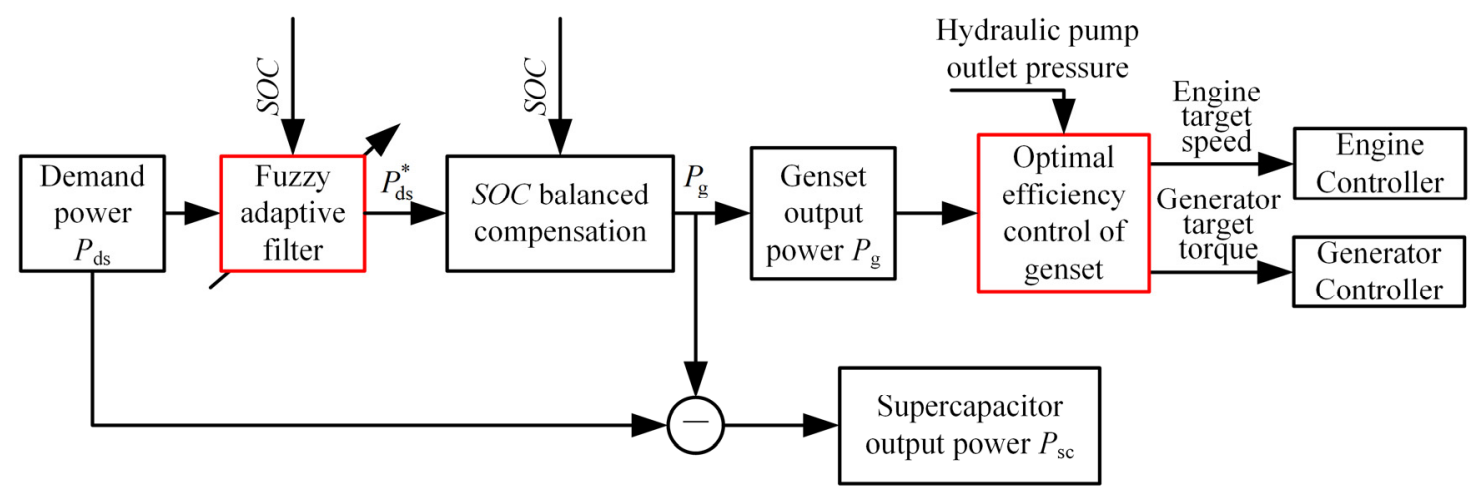

Figure 7. Flow chart of adaptive smoothing power following the energy management strategy.

Fuzzy adaptive filter

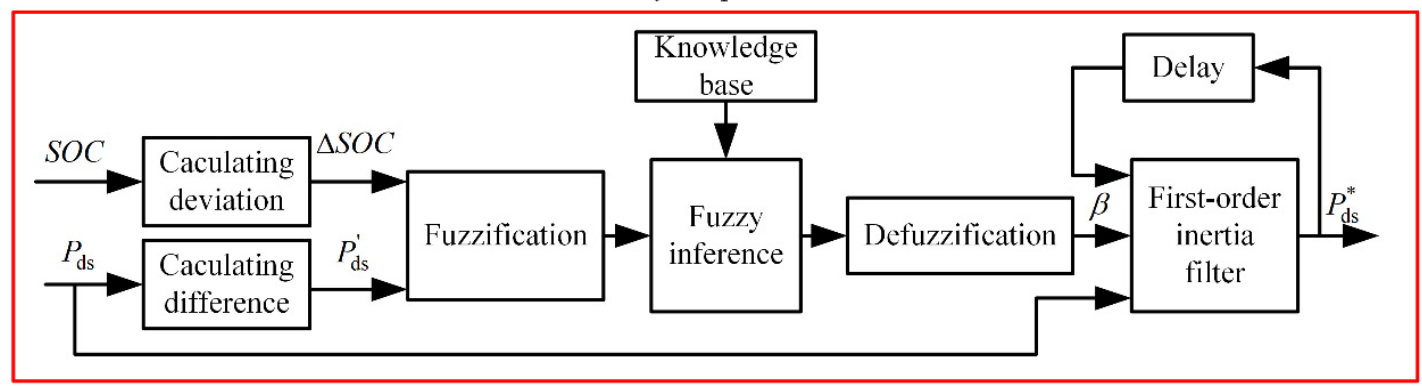

Figure 8. Schematic diagram of smoothing power based on the fuzzy adaptive filter.

The variables in Figure 8 can be expressed as

$$
\begin{gathered}
\triangle S O C=S O C-\left(S O C_{\mathrm{hi}}+S O C_{\mathrm{lo}}\right) / 2, \\
P_{\mathrm{ds}}^{\prime}=P_{\mathrm{ds}}(t)-P_{\mathrm{ds}}(t-1),
\end{gathered}
$$

where $\triangle S O C$ is the deviation of $S O C ; S O C_{\mathrm{hi}}$ and $S O C_{\mathrm{lo}}$ are the high and low threshold value, respectively; $P_{\mathrm{ds}}^{\prime}$ is the difference of the demand power; and $P_{\mathrm{ds}}$ is the demand power.

The first-order inertia filter can be developed by

$$
P_{\mathrm{ds}}^{*}(t)=\beta P_{\mathrm{ds}}(t)+(1-\beta) P_{\mathrm{ds}}^{*}(t-1),
$$

where $P_{\mathrm{ds}}^{*}$ is the filtered demand power and $\beta$ is the filter coefficient.

The SOC deviation and the demand power difference are normalized as the fuzzy logic inputs, which can be shown as

$$
\begin{gathered}
\triangle S O C_{\text {in }}=\Delta S O C / \max (\triangle S O C), \\
P_{\mathrm{ds}, \text { in }}^{\prime}=P_{\mathrm{ds}}^{\prime} / \max \left(P_{\mathrm{ds}}^{\prime}\right),
\end{gathered}
$$

where $\triangle S O C_{\mathrm{in}}$ and $P_{\mathrm{ds} \text {,in }}^{\prime}$ are the normalized $S O C$ deviation and demand power difference, respectively.

The degree of membership (DOM) values of input and output variables of the fuzzy logic controller are defined as shown in Figure 9. Because the filter will introduce a delay effect of input signals, the SOC deviation is entered here in order to prevent the SOC from exceeding its limits. Table 3 shows the fuzzy logic rules in the knowledge base. The basic formulation principle of the rule table is that the demand power is filtered and the SOC is kept within the predetermined range as much as possible. 

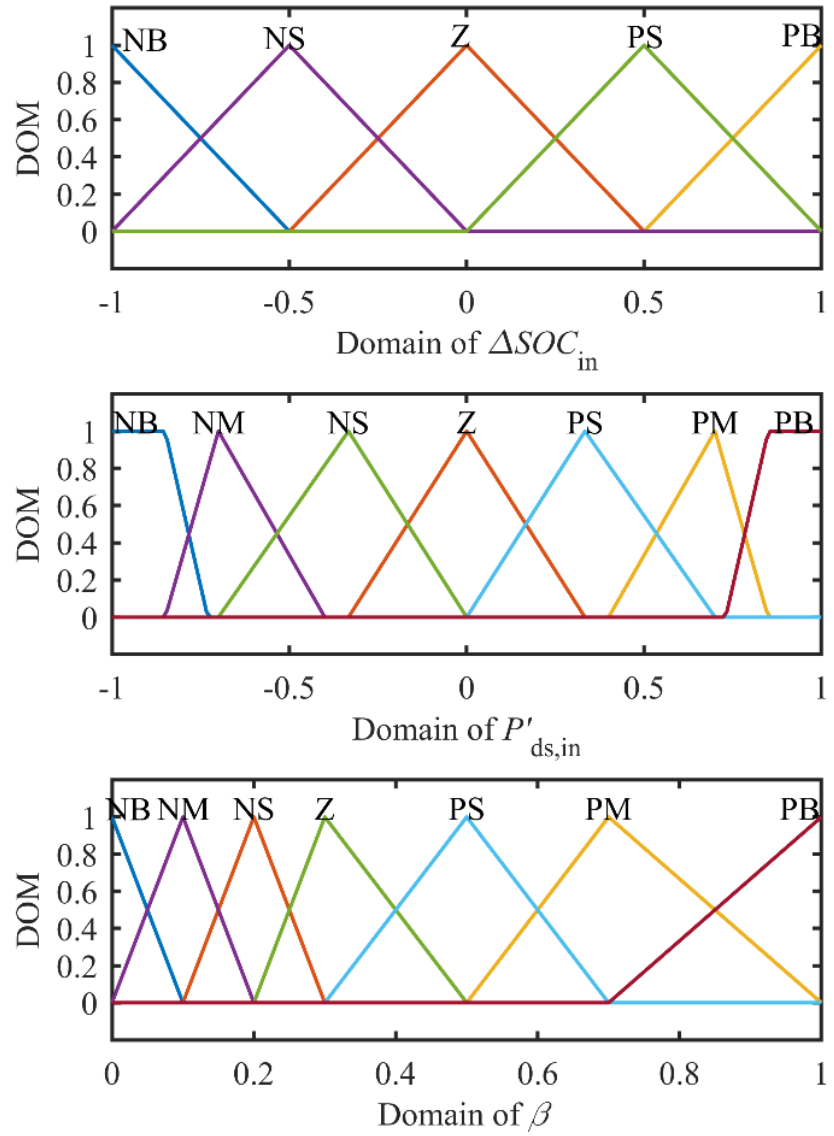

Figure 9. Membership function of input and output variables.

Table 3. Fuzzy logic rules.

\begin{tabular}{|c|c|c|c|c|c|c|c|c|}
\hline & & \multicolumn{7}{|c|}{$P_{\mathrm{ds}, \text { in }}^{\prime}$} \\
\hline & & NB & NM & NS & $\mathbf{Z}$ & PS & PM & PB \\
\hline \multirow{5}{*}{$\triangle S O C_{\text {in }}$} & NB & NB & NB & NM & PB & PB & PB & PB \\
\hline & NS & NB & NM & NM & $\mathrm{Z}$ & PS & PM & PB \\
\hline & $\mathrm{Z}$ & NS & NM & NM & NB & NM & NM & NS \\
\hline & PS & PB & PM & PS & $\mathrm{Z}$ & NM & NM & NB \\
\hline & PB & PB & PB & PB & $\mathrm{PB}$ & NM & NB & NB \\
\hline
\end{tabular}

By employing the min-max inference approach of the Mamdani type and the centroid method for defuzzification, the output map of the fuzzy inference system, that is, the fuzzy control table, can be achieved, as shown in Figure 10. The control map is a symmetrical valley type about its center, since the filtering function can be as large as possible within the $S O C$ limits when the difference in the demand power and the deviation of $S O C$ are opposite in sign.

\subsubsection{Correctional Optimal Efficiency Map}

The module of optimal efficiency control of the genset is the other crucial part of ASPF, as shown in Figure 11. This module takes the demand power of generation and the pressure of the hydraulic pump as inputs to calculate the generator target torque and the engine target speed as outputs. The input mechanical power of the generator can be calculated by

$$
P_{\mathrm{g}, \mathrm{m}}=\frac{P_{\mathrm{g}}}{\eta_{\mathrm{g}}\left(T_{\mathrm{g}, \text { est }}, n_{\mathrm{g}, \mathrm{est}}\right)},
$$


where $P_{\mathrm{g}, \mathrm{m}}$ is the input mechanical power of the generator; $P_{\mathrm{g}}$ is the generating electric power; $T_{\mathrm{g}, \mathrm{est}}$ and $n_{\mathrm{g}, \text { est }}$ are the estimated torque and speed, respectively; and $\eta_{\mathrm{g}}$ is the efficiency interpolation function.

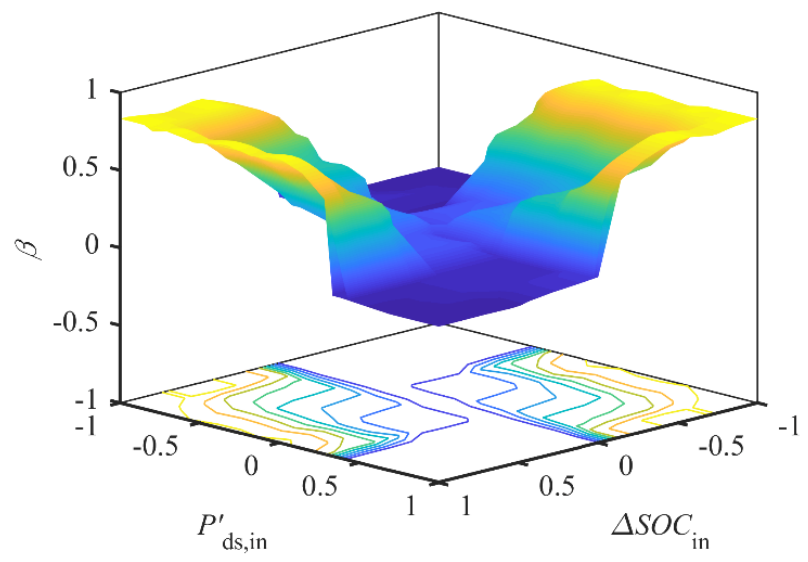

Figure 10. Output map of the fuzzy inference system.

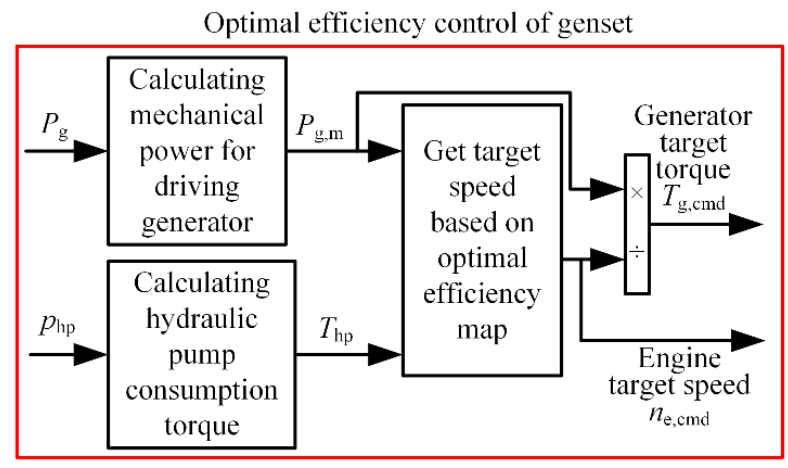

Figure 11. Control principle of the genset based on the optimal efficiency map.

The optimal efficiency map is the core of this module. The problem of searching the optimal efficiency map can be converted into a problem of searching the optimal curves under different input torques of the hydraulic pump by using Equation (30). The consumed torque of the hydraulic pump can be calculated by Equation (19). Through changing the hydraulic pump torque continuously and searching each optimal efficiency curve of the genset at each torque value, the optimal efficiency map can finally be obtained, as shown in Figure 12.

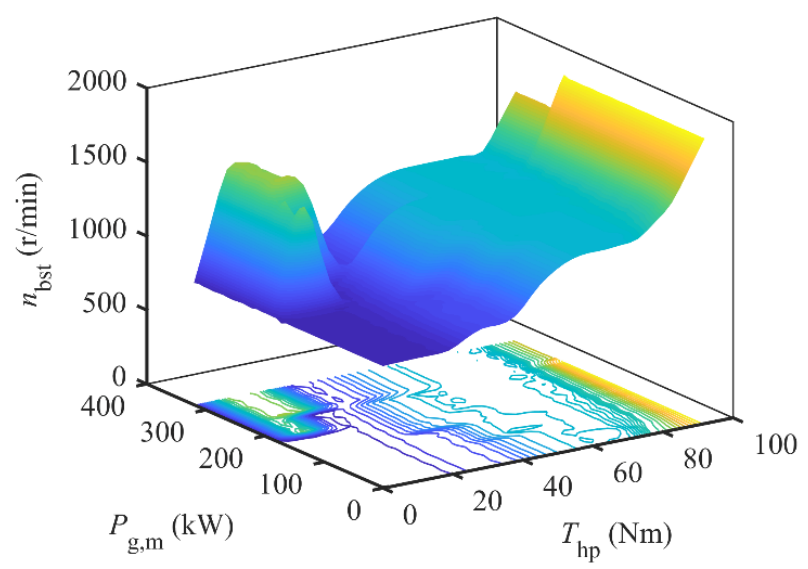

Figure 12. Optimal efficiency map of the genset. 
The relationship between the input torque of the generator, the engine torque, and the hydraulic pump torque can be expressed as

$$
T_{\mathrm{g}}=T_{\mathrm{e}}-T_{\mathrm{hp}},
$$

where $T_{\mathrm{g}}$ is the input torque of the generator.

\section{HEB HIL Platform}

In order to validate the real-time control effect of the proposed strategy, an HEB controller HIL experimental platform was developed, as shown in Figure 13. The control strategy was converted into an executable $\mathrm{C}$ code and integrated with the controller underlying software, and was then downloaded in the vehicle control unit (VCU). Meanwhile, the controlled object model was downloaded to the dSPACE Autobox simulator (DS1103, dSPACE, Paderborn, North Rhine-Westphalia, Germany). The real-time supervisory control interface was developed on the host computer monitor. The communication network among the VCU, the Autobox, and the host computer monitor was established with the means of the control area network (CAN) and transmission control protocol/internet protocol (TCP/IP).

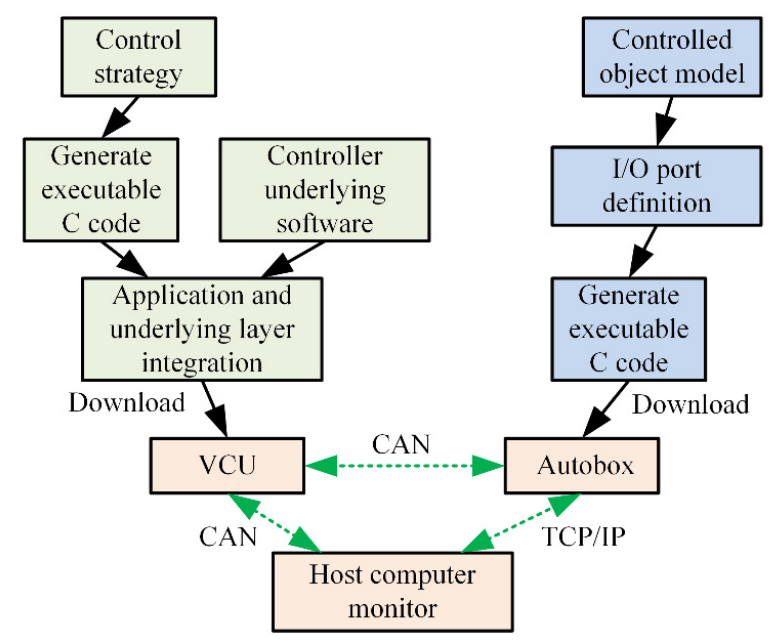

Figure 13. Testing program of hardware in loop (HIL) of the HEB controller.

Figure 14 shows the developed HEB HIL test platform, which could be used to test and compare the real-time control effect of online strategies. The model incorporated in the HIL platform was validated by employing the practical HEB real bulldozing process data, as shown in [61]. Therefore, the combination of the validated model and the real VCU could test the real-time performance and effectiveness of the proposed control strategy to some extent.

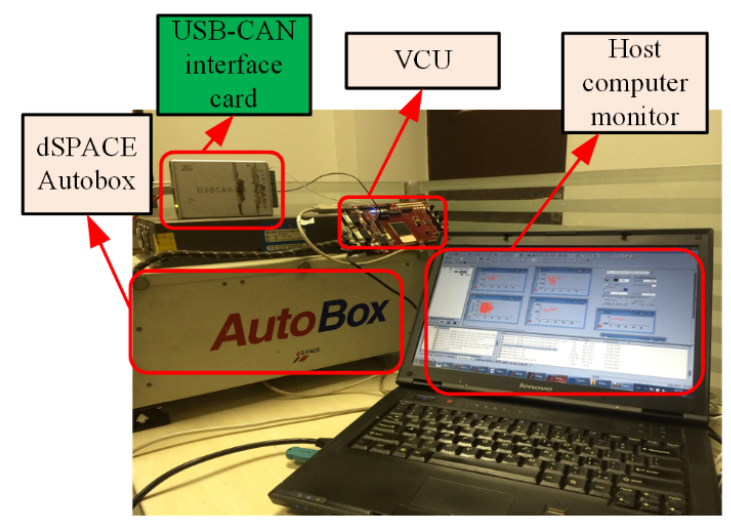

Figure 14. Test platform of HEB HIL. 


\section{Results and Discussion}

Due to the lack of a standard drive cycle of bulldozers like that of automobiles, a representative actual drive cycle of the bulldozer, which was extracted and constructed from a large number of bulldozing experimental data in our previous research [7], was adopted for simulation and comparison. Figure 15 shows the drive cycle, including the bulldozing stage and empty returning stage. The bulldozing stage can be further divided into cutting-soil, transporting-soil, and unloading-soil stages.
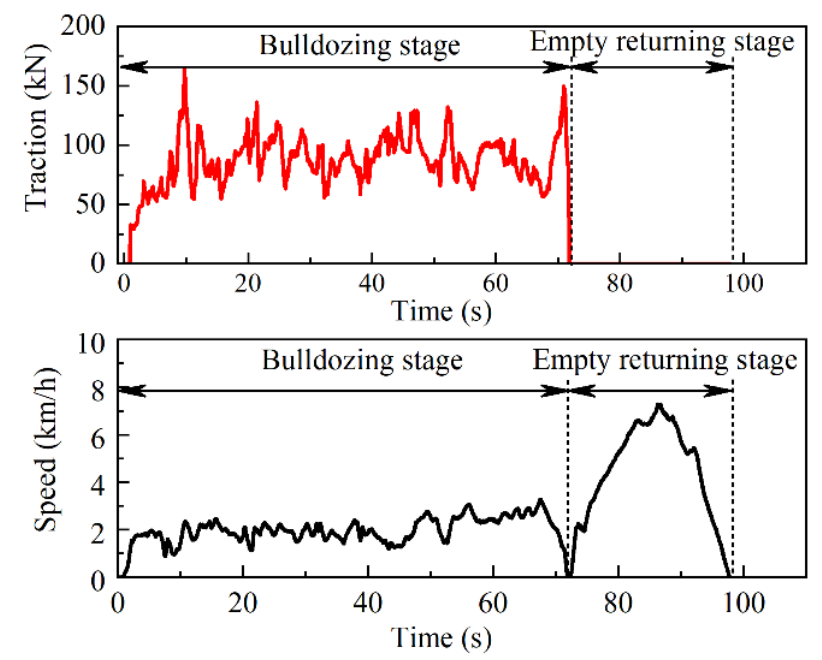

Figure 15. Traction and speed of a representative actual drive cycle.

In order to validate and compare the control effect, three control strategies were compared under the representative actual drive cycle. Table 4 describes the compared strategies: a power following strategy in a preliminarily practical application (PF1), a typical power following strategy based on the engine minimum fuel consumption curve (PF2), and the proposed strategy (ASPF). Figure 16, Figure 17, Figure 18 and Table 5 show the comparison results.

Table 4. Comparison of different control strategies.

\begin{tabular}{|c|c|}
\hline Control & Description \\
\hline PF1 & $\begin{array}{l}\text { A power following control strategy used in our previous real HEB experiment, } \\
\text { where the genset follows the demand power, and the engine speed follows the } \\
\text { accelerator and remains within } 1300 \text { to } 1800 \mathrm{r} / \mathrm{min} .\end{array}$ \\
\hline PF2 & $\begin{array}{l}\text { A typical power following control strategy based on the engine minimum fuel } \\
\text { consumption curve in the series powertrain. }\end{array}$ \\
\hline ASPF & $\begin{array}{c}\text { Proposed adaptive smoothing power following control strategy based on the } \\
\text { optimal efficiency map. }\end{array}$ \\
\hline
\end{tabular}

Table 5. Comparison of fuel consumption.

\begin{tabular}{ccccc}
\hline Vehicle & Control & FC (L) & EFC (L) & EFSR (\%) \\
\hline HMB & - & 0.671 & 0.671 & - \\
HEB & PF1 & 0.569 & 0.568 & 15.4 \\
& PF2 & 0.537 & 0.538 & 19.8 \\
& ASPF & 0.517 & 0.515 & 23.2 \\
\hline
\end{tabular}

FC: fuel consumption; EFC: equivalent fuel consumption; EFSR: equivalent fuel saving rate. 

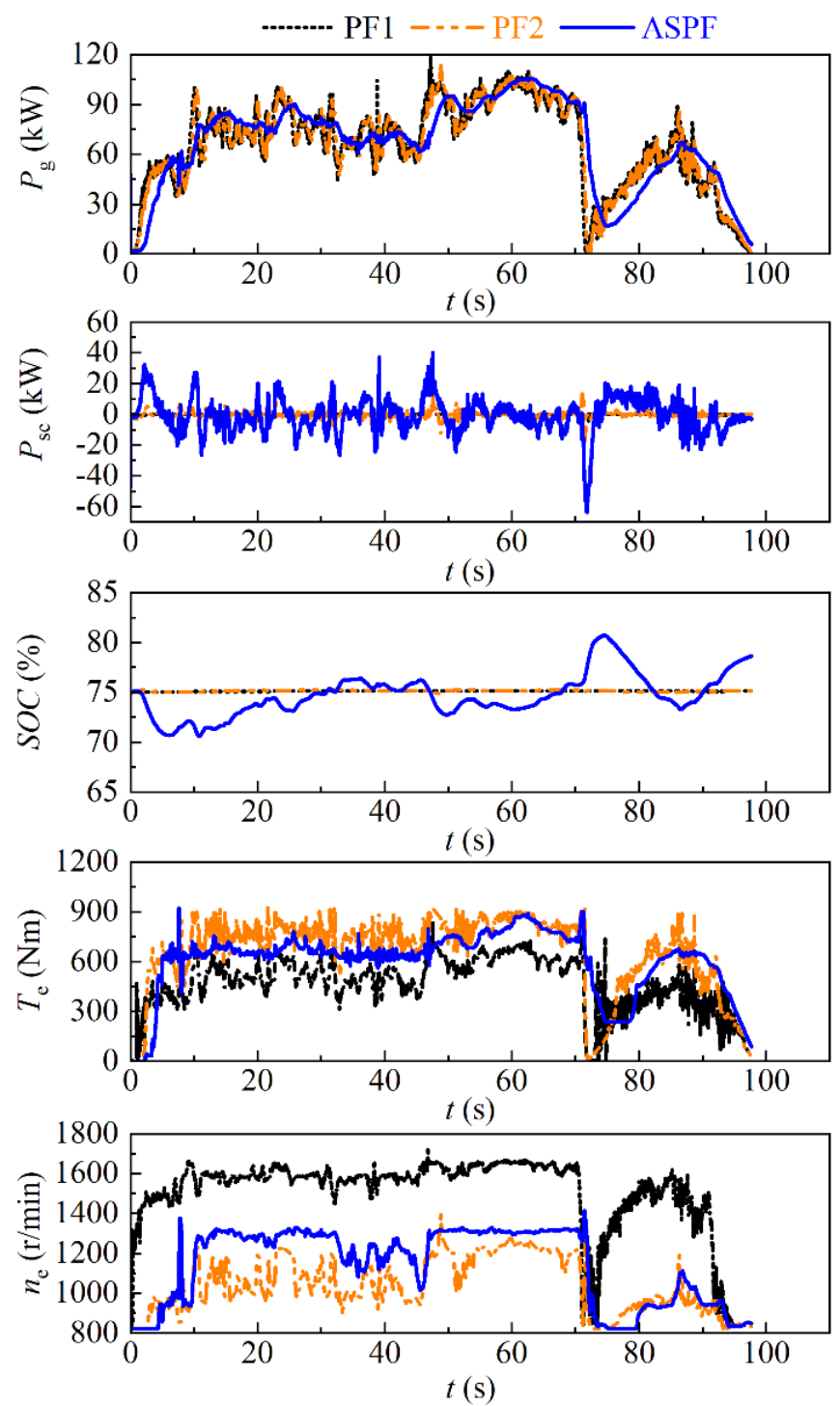

Figure 16. Comparison of operating parameters of key powertrain components.
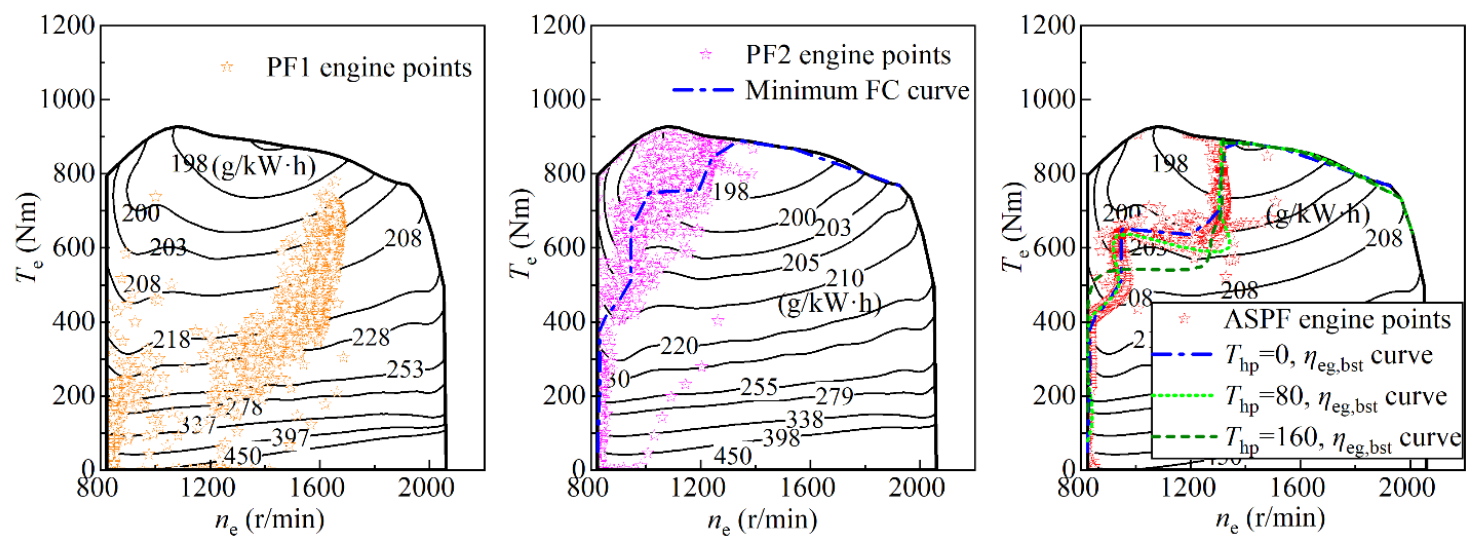

Figure 17. Distribution of engine working points. FC: fuel consumption, $\eta_{\mathrm{eg}, \mathrm{bst}}$ : the best efficiency of the genset. 

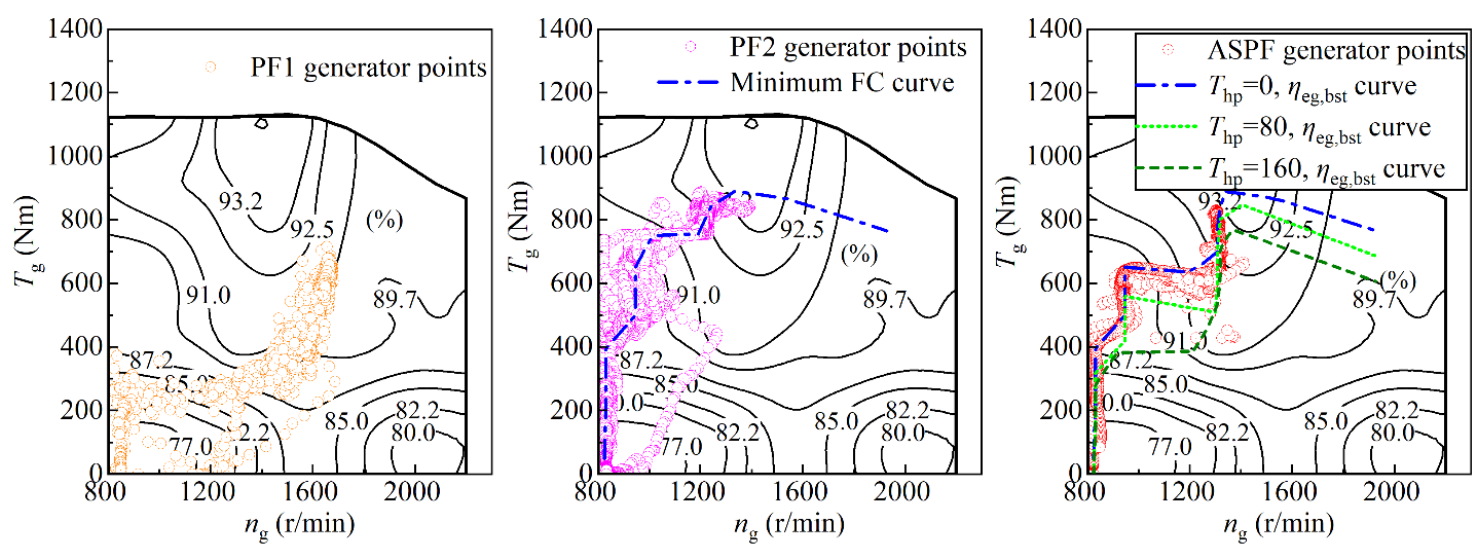

Figure 18. Distribution of generator working points.

Figure 16 shows the comparison of a group of key powertrain parameters, including the generator output power $P_{\mathrm{g}}$, supercapacitor output power $P_{\mathrm{sc}}$, supercapacitor $S O C$, engine torque $T_{\mathrm{e}}$, and engine speed $n_{\mathrm{e}}$. It can be observed that the generator output power fiercely fluctuates and follows the demand power under the PF1 and PF2. However, the change of generator output power is relatively smooth under the ASPF. The supercapacitor power under the ASPF is larger and fluctuates more than that under the PF1 and PF2. Meanwhile, the SOC of the ASPF varies within a permissible range. The first three subgraphs of Figure 16 illustrate that the self-adaptive filter algorithm in the ASPF can smoothen the power adaptively and keep the SOC within pre-set limits simultaneously by timely adjustment of the filter coefficient, which can prompt higher engagement and take full advantage of the high efficiency of the supercapacitor. The fourth and fifth subgraphs show that ASPF makes the engine speed and torque more stable, especially relative to the PF2 based on the trajectory, through smoothing the genset output power. Therefore, the ASPF can play a positive role in stabilizing the working points of the engine and generator, which can achieve a reduction of the transient energy loss.

Figure 17 compares the engine working points with different strategies under the same representative drive cycle. It can be seen that the engine working point distribution with PF1 is widespread and mainly within the speed range from 1300 to $1800 \mathrm{r} / \mathrm{min}$ in different loads, whereas it is far away from the low fuel consumption area. From the middle subgraph, we can see that the engine operating points of PF2 are distributed around the minimum fuel consumption curve. However, they could not coincide with the curve because of their dramatic fluctuation and insufficient response on the timeline shown in Figure 16. The left subgraph shows that the engine working point distribution of ASPF is very close to the pre-set optimal efficiency curves of combining the engine with the generator under different hydraulic pump consumed torque. This relatively concentrated distribution is the result of the effect of the adaptive filter link shown in the above graph.

Figure 18 compares the generator working point distribution with three control strategies under the same drive cycle. It can be seen that the distribution shape of the generator points is similar to that of the engine points on account of the coaxial junction of the engine and the generator. The generator working points of PF1 and PF2 are more widely distributed than those of ASPF for the adaptive filter. The difference between the generator torque below and the engine torque above is the hydraulic pump consumed torque, which is also reflected on the joint optimal efficiency curves in the above and below graphs. The ASPF keeps the generator points along the optimal efficiency curves as much as possible, in which following the routes can result in a greater generator efficiency.

The fuel consumption of the three control strategies and the prototype of the traditional hydro-mechanical bulldozer (HMB) under the same simulated drive cycle is shown in Table 5 . The equivalent fuel consumption (EFC) was obtained from balancing the supercapacitor SOC. The equivalent fuel saving ratio (EFSR) is the comparison of EFC, reflecting the energy consumption comparison. The HEB equipped with the ASPF strategy can achieve 23.2\% EFSR compared with the 
HMB. However, it can only achieve $15.4 \%$ and $19.8 \%$ EFSR with the PF1 and PF2 strategy, respectively. The ASPF strategy can improve EFSR by $7.8 \%$ and $3.4 \%$ with respect to the PF1 and PF2 strategy, which indicates that the proposed strategy is more effective.

\section{Conclusions}

An adaptive smoothing power following (ASPF) control strategy based on an optimal efficiency map for a series tracked HEB has been proposed by considering its operation characteristics in this research. The three problems of increased fuel consumption presented in previous control studies to be solved by this strategy, including frequent fluctuation of the engine working points, deviation of the genset working points from the pre-set target trajectory due to a lack of response, and interference of the hydraulic pump consumed torque, were analyzed in detail. The whole HEB system simulation model with a novel transient fuel consumption model based on BPNN was established. The HEB HIL platform was then developed to evaluate the real-time performance and the effect of the strategy in a practical application. The methodology of the proposed control strategy is based on fuzzy control theory, real-based control, and the optimization method. The method of effect verification is incorporated on the basis of the adoption of a validated simulation model and an HIL test platform.

The ASPF strategy was compared with two strategies: a power following strategy in a preliminarily practical application (PF1) and a typical power following strategy based on the engine minimum fuel consumption curve (PF2). The results show that (1) the ASPF strategy can significantly reduce the fluctuation and pre-set trajectory deviation of the engine and generator working points; (2) the EFSR can be improved by about $7.8 \%$ and $3.4 \%$ with the ASPF strategy compared with the PF1 and PF2 strategy; and (3) the ASPF strategy is able to perform well in a real controller. It can be concluded that the proposed strategy can be effective and efficient in practical online HEB applications. The results also show that the discovered problems indeed exist and the corresponding control strategies are valid in HEB.

Filed tests of the HEB with the ASPF strategy will be carried out to further advance the real application value in our future research. The limitation of the ASPF strategy in real applications relative to previous work is that it should obtain the pressure signal of the hydraulic pump as the input for calculation, so a pressure sensor should be placed in the outlet of the hydraulic pump. Nevertheless, the proposed strategy and the problems solved and focused on in this paper are significant references for other types of HECMs. Moreover, future study will also explore comparisons of the ASPF online strategy and the optimization algorithm-based theoretical offline strategy to evaluate its potential for improvement.

Author Contributions: Conceptualization, B.Z., S.G., and X.Z.; data curation, B.Z., Q.X., and L.T.; formal analysis, B.Z., Q.X., and L.T.; methodology, B.Z., S.G., and X.Z.; project administration, X.Z.; resources, X.Z.; supervision, S.G. and X.Z.; writing_-original draft, B.Z.; writing_-review and editing, B.Z. All authors have read and agreed to the published version of the manuscript.

Funding: This study is sponsored by the National Key R\&D Program of China (2016YFD0700703). The authors would like to thank the anonymous reviewers for their reviews and comments.

Conflicts of Interest: The authors declare no conflict of interest.

\section{Nomenclature}

\section{Variables}

slope angle, filter coefficient efficiency, \% ground deformation resistance coefficient rotary mass coefficient density, $\mathrm{g} / \mathrm{L}$ time constant 


\begin{tabular}{|c|c|}
\hline$\varphi$ & track slip rate, $\%$ \\
\hline$\omega$ & angular speed, $\mathrm{rad} / \mathrm{s}$ \\
\hline$b e$ & specific fuel consumption, $\mathrm{g} /(\mathrm{kWh})$ \\
\hline$B$ & fuel consumption rate, $\mathrm{L} / \mathrm{h}$ \\
\hline$c$ & specific heat capacity, $\mathrm{J} /\left(\mathrm{kg} \cdot{ }^{\circ} \mathrm{C}\right)$ \\
\hline C & capacitor, F \\
\hline$f$ & function \\
\hline$F$ & force, $\mathrm{N}$ \\
\hline$g$ & gravitational acceleration, $\mathrm{m} / \mathrm{s}^{2}$ \\
\hline$I$ & current, A \\
\hline$J$ & rotational inertia, $\mathrm{kg} \cdot \mathrm{m}^{2}$ \\
\hline$m$ & mass, $\mathrm{kg}$ \\
\hline$n$ & speed, $\mathrm{r} / \mathrm{min}$ \\
\hline$p$ & pressure, $\mathrm{Pa}$ \\
\hline$P$ & power, $\mathrm{W}$ \\
\hline$q$ & displacement, $\mathrm{ml} / \mathrm{r}$ \\
\hline$Q$ & flow, $\mathrm{L} / \mathrm{min}$ \\
\hline$r$ & radius, $\mathrm{m}$ \\
\hline$R$ & correction factor \\
\hline$R e$ & resistance, $\Omega$; \\
\hline$s$ & Laplace operator \\
\hline SOC & state of charge \\
\hline$t$ & time, $\mathrm{s}$ \\
\hline$T$ & torque, $\mathrm{Nm}$ \\
\hline Tem & temperature, ${ }^{\circ} \mathrm{C}$ \\
\hline$U$ & voltage, $\mathrm{V}$ \\
\hline$v$ & velocity, $\mathrm{m} / \mathrm{s}$ \\
\hline \multicolumn{2}{|c|}{ Subscripts } \\
\hline a & air \\
\hline $\mathrm{b}$ & bulldozing \\
\hline bp & back propagation neural network \\
\hline $\mathrm{cl}$ & current limit \\
\hline $\mathrm{cmd}$ & command \\
\hline coul & coulombic \\
\hline ds & drive system \\
\hline e & engine \\
\hline em & electric machine \\
\hline est & estimated \\
\hline $\mathrm{fu}$ & fuel \\
\hline g & generator \\
\hline $\mathrm{h}$ & heat \\
\hline hi & high \\
\hline hp & hydraulic pump \\
\hline in & input \\
\hline ini & initial \\
\hline lo & low \\
\hline $\mathrm{m}$ & mechanical \\
\hline $\mathrm{s}$ & steady state \\
\hline $\mathrm{sc}$ & supercapacitor \\
\hline $\mathrm{t}$ & transient state \\
\hline ul & voltage limit \\
\hline veh & vehicle \\
\hline
\end{tabular}




$\begin{array}{ll}\begin{array}{l}\text { Superscripts } \\ \text { br } \\ \text { chg }\end{array} & \begin{array}{l}\text { braking process } \\ \text { charging process } \\ \text { dis }\end{array} \\ \text { dr } & \text { discharging process } \\ \text { Abbiving process }\end{array}$

\section{References}

1. Tran, D.D.; Vafaeipour, M.; El Baghdadi, M.; Barrero, R.; Van Mierlo, J.; Hegazy, O. Thorough state-of-the-art analysis of electric and hybrid vehicle powertrains: Topologies and integrated energy management strategies. Renew. Syst. Energ. Rev. 2020, 119, 109596. [CrossRef]

2. Zhang, Y.; Guo, C.; Li, G.; Liu, Y.; Chen, Z. Cooperative control strategy for plug-in hybrid electric vehicles based on a hierarchical framework with fast calculation. J. Clean. Prod. 2020, 251, 119627. [CrossRef]

3. Zhang, B.; Yang, F.; Teng, L.; Ouyang, M.; Guo, K.; Li, W.; Du, J. Comparative analysis of technical route and market development for light-duty PHEV in China and the US. Energies 2019, 12, 3753. [CrossRef]

4. Xu, B.; Rathod, D.; Zhang, D.; Yebi, A.; Zhang, X.; Li, X.; Filipi, Z. Parametric study on reinforcement learning optimized energy management strategy for a hybrid electric vehicle. Appl. Energy 2020, 259, 114200. [CrossRef]

5. He, X.; Jiang, Y. Review of hybrid electric systems for construction machinery. Autom. Constr. 2018, 92, 286-296. [CrossRef]

6. Wang, J.; Yang, Z.; Liu, S.; Zhang, Q.; Han, Y. A comprehensive overview of hybrid construction machinery. Adv. Mech. Eng. 2016, 8. [CrossRef]

7. Zhang, B.; Zhang, X.; Xi, L.; Sun, C. Development of a representative operation cycle characterized by dual time series for bulldozers. Proc. Inst. Mech. Eng. D J. Aut. Eng. 2017, 231, 1818-1828. [CrossRef]

8. Hong, W.; FengChun, S. Dynamic modeling and simulation on a hybrid power system for dual-motor-drive electric tracked bulldozer. Appl. Mech. Mater. 2014, 494, 229-233.

9. Song, Q.; Zeng, P.; He, S.; Wang, H. Power flowing control strategy of series hybrid tracked bulldozer at the typical working condition. J. Mech. Eng. 2014, 50, 136-142. [CrossRef]

10. Wang, H.; Huang, Y.; Khajepour, A.; Song, Q. Model predictive control-based energy management strategy for a series hybrid electric tracked vehicle. Appl. Energy 2016, 182, 105-114. [CrossRef] 
11. Hong, W. Research on Dynamic Modeling and Control Strategy for Hybrid Tracked Bulldozer; Beijing Institute of Technology: Beijing, China, 2015.

12. Azmat, M.; Kummer, S. Potential applications of unmanned ground and aerial vehicles to mitigate challenges of transport and logistics-related critical success factors in the humanitarian supply chain. Asian J. Sustain. Soc. Responsib. 2020, 5, 3. [CrossRef]

13. Azmat, M.; Kummer, S.; Moura, L.T.; Gennaro, F.D.; Moser, R. Future outlook of highway operations with implementation of innovative technologies like AV, CV, IOT and big data. Logistics 2019, 3, 15. [CrossRef]

14. Wintersberger, S.; Azmat, M.; Kummer, S. Are we ready to ride autonomous vehicles? A pilot study on austrian consumers' perspective. Logistics 2019, 3, 20. [CrossRef]

15. Shabbir, W.; Evangelou, S.A. Threshold-changing control strategy for series hybrid electric vehicles. Appl. Energy 2019, 235, 761-775. [CrossRef]

16. Li, H.; Ravey, A.; N'Diaye, A.; Djerdir, A. A novel equivalent consumption minimization strategy for hybrid electric vehicle powered by fuel cell, battery and supercapacitor. J. Power Sources 2018, 395, 262-270. [CrossRef]

17. Chen, S.Y.; Wu, C.H.; Hung, Y.H.; Chung, C.T. Optimal strategies of energy management integrated with transmission control for a hybrid electric vehicle using dynamic particle swarm optimization. Energy 2018, 160, 154-170. [CrossRef]

18. Du, G.; Zou, Y.; Zhang, X.; Kong, Z.; Wu, J.; He, D. Intelligent energy management for hybrid electric tracked vehicles using online reinforcement learning. Appl. Energy 2019, 251, 113388. [CrossRef]

19. Guo, Q.; Zhao, Z.; Shen, P.; Zhan, X.; Li, J. Adaptive optimal control based on driving style recognition for plug-in hybrid electric vehicle. Energy 2019, 186, 115824. [CrossRef]

20. Enang, W.; Bannister, C. Modelling and control of hybrid electric vehicles (a comprehensive review). Renew. Sustain. Energ. Rev. 2017, 74, 1210-1239. [CrossRef]

21. Wang, Y.; Wang, X.; Sun, Y.; You, S. Model predictive control strategy for energy optimization of series-parallel hybrid electric vehicle. J. Clean. Prod. 2018, 199, 348-358. [CrossRef]

22. Lu, X.; Wu, Y.; Lian, J.; Zhang, Y.; Chen, C.; Wang, P.; Meng, L. Energy management of hybrid electric vehicles: A review of energy optimization of fuel cell hybrid power system based on genetic algorithm. Energy Convers. Manag. 2020, 205, 112474. [CrossRef]

23. Huang, Y.; Wang, H.; Khajepour, A.; Li, B.; Ji, J.; Zhao, K.; Hu, C. A review of power management strategies and component sizing methods for hybrid vehicles. Renew. Sustain. Energ. Rev. 2018, 96, 132-144. [CrossRef]

24. Wu, Y.; Tan, H.; Peng, J.; Zhang, H.; He, H. Deep reinforcement learning of energy management with continuous control strategy and traffic information for a series-parallel plug-in hybrid electric bus. Appl. Energy 2019, 247, 454-466. [CrossRef]

25. Wu, J.; Wang, X.; Li, L.; Qin, C.; Du, Y. Hierarchical control strategy with battery aging consideration for hybrid electric vehicle regenerative braking control. Energy 2018, 145, 301-312. [CrossRef]

26. Li, H.; Ravey, A.; N'Diaye, A.; Djerdir, A. Online adaptive equivalent consumption minimization strategy for fuel cell hybrid electric vehicle considering power sources degradation. Energy Convers. Manag. 2019, 192, 133-149. [CrossRef]

27. Gong, J.; Zhang, D.; Guo, Y.; Liu, C.; Zhao, Y.; Hu, P.; Quan, W. Power control strategy and performance evaluation of a novel electro-hydraulic energy-saving system. Appl. Energy 2019, 233, 724-734. [CrossRef]

28. Shi, Y.; Xia, Y.; Zhang, Y.; Yao, Z. Intelligent identification for working-cycle stages of excavator based on main pump pressure. Autom. Constr. 2020, 109, 102991. [CrossRef]

29. Yu, Y.X.; Ahn, K.K. Optimization of energy regeneration of hybrid hydraulic excavator boom system. Energy Convers. Manag. 2019, 183, 26-34. [CrossRef]

30. Larsson, L.V.; Ericson, L.; Uebel, K.; Krus, P. Low-level control of hybrid hydromechanical transmissions for heavy mobile working machines. Energies 2019, 12, 1683. [CrossRef]

31. Li, T.; Liu, H.; Ding, D. Predictive energy management of fuel cell supercapacitor hybrid construction equipment. Energy 2018, 149, 718-729. [CrossRef]

32. Hippalgaonkar, R.; Ivantysynova, M. Optimal power management of hydraulic hybrid mobile machines-part I: Theoretical studies, modeling and simulation. J. Dyn. Syst. T Asme 2016, 138. [CrossRef]

33. Nilsson, T.; Froberg, A.; Aslund, J. Predictive control of a diesel electric wheel loader powertrain. Control. Eng. Pract. 2015, 41, 47-56. [CrossRef] 
34. Zhou, H.; Zhao, P.Y.; Chen, Y.L.; Yang, H.Y. Prediction-based stochastic dynamic programming control for excavator. Autom. Constr. 2017, 83, 68-77. [CrossRef]

35. Kim, H.; Yoo, S.; Cho, S.; Yi, K. Hybrid control algorithm for fuel consumption of a compound hybrid excavator. Autom. Constr. 2016, 68, 1-10. [CrossRef]

36. Chen, Q.; Lin, T.; Ren, H. Parameters optimization and control strategy of power train systems in hybrid hydraulic excavators. Mechatronics 2018, 56, 16-25. [CrossRef]

37. Li, T.; Huang, L.; Liu, H. Energy management and economic analysis for a fuel cell supercapacitor excavator. Energy 2019, 172, 840-851. [CrossRef]

38. Zhu, Q.; Wang, Q.F. Real-time energy management controller design for a hybrid excavator using reinforcement learning. J. Zhejiang Univ. Sci. A 2017, 18, 855-870. [CrossRef]

39. Zhou, C.; Xu, H.C.; Ding, L.Y.; Wei, L.C.; Zhou, Y. Dynamic prediction for attitude and position in shield tunneling: A deep learning method. Autom. Constr. 2019, 105, 16. [CrossRef]

40. Zhou, H.; Zhao, P.Y.; Chen, Y.L. Fuzzy logic control for a hydraulic hybrid excavator based on torque prediction and genetic algorithm optimization. Proc. Inst. Mech. Eng. D J. Aut. Eng. 2018, 232, 983-994. [CrossRef]

41. Liang, X.J.; Wu, W.R. Control strategy of energy saving for power system in hydraulic surface drilling rig. J. Braz. Soc. Mech. Sci. Eng. 2018, 40, 8.

42. Ye, Y.; Yin, C.B.; Gong, Y.; Zhou, J.J. Position control of nonlinear hydraulic system using an improved PSO based PID controller. Mech. Syst. Sig. Process. 2017, 83, 241-259. [CrossRef]

43. Truong, D.Q.; Marco, J.; Greenwood, D.; Harper, L.; Corrochano, D.G.; Yoon, J.I. Challenges of micro/mild hybridisation for construction machinery and applicability in UK. Renew. Sustain. Energ. Rev. 2018, 91, 301-320. [CrossRef]

44. Zhang, B.; Zhang, X.; Zhang, X.; Xi, L. Development of simulation model for series hybrid electric crawler bulldozer (SHECB) based on ADVISOR. Adv. Mater. Res. 2013, 732, 337-343. [CrossRef]

45. Betz, M.D.; Casey, K.A.; Garnett, S.C.; Liang, C.C.; Tonsor, A.J.; Vanderham, M.E. Electric Powertrain for Machine. U.S. Patent No. 7,950,481, 31 May 2011.

46. Cao, T. Evaluation of Greenhouse Gas and Criteria Emissions from Conventional and Hybrid Off-Road Equipment; University of California, Riverside: Riverside, CA, USA, 2014.

47. Hong, W.; Yanjun, H.; Amir, K.; Chuan, H.; Amir, K. Electrification of Heavy-Duty Construction Vehicles; Morgan \& Claypool: Williston, VT, USA, 2017; p. 1.

48. Wang, H.; Huang, Y.; Khajepour, A.; He, H.; Lv, C. Mpc-Based Power Management Strategy for a Series Hybrid Electric Tracked Bulldozer. In Proceedings of the 2017 IEEE International Conference on Industrial Technology (ICIT), Toronto, ON, Canada, 22-25 March 2017; IEEE: Piscataway, NJ, USA, 2017; pp. 1403-1408.

49. Wang, H.; Huang, Y.; He, H.; Lv, C.; Liu, W.; Khajepour, A. Chapter 5-Energy Management of Hybrid Electric Vehicles. In Modeling, Dynamics and Control of Electrified Vehicles; Zhang, H., Cao, D., Du, H., Eds.; Woodhead Publishing: Sawston, UK, 2018; pp. 159-206.

50. Wang, H.; Huang, Y.; Khajepour, A.; He, H.; Cao, D. A novel energy management for hybrid off-road vehicles without future driving cycles as a priori. Energy 2017, 133, 929-940. [CrossRef]

51. Wang, H.; Huang, Y.; Khajepour, A. Cyber-physical control for energy management of off-road vehicles with hybrid energy storage systems. IEEE/ASME Trans. Mechatron. 2018, 23, 2609-2618. [CrossRef]

52. Han, X.; He, H.; Wu, J.; Peng, J.; Li, Y. Energy management based on reinforcement learning with double deep Q-learning for a hybrid electric tracked vehicle. Appl. Energy 2019, 254, 113708. [CrossRef]

53. Wei, S.; Zou, Y.; Sun, F.; Christopher, O. A pseudospectral method for solving optimal control problem of a hybrid tracked vehicle. Appl. Energy 2017, 194, 588-595. [CrossRef]

54. Zhang, B. Study on Energy Saving Mechanism and Control Strategy of Hybrid Electric Bulldozer; Beijing Jiaotong University: Beijing, China, 2017.

55. Markel, T.; Brooker, A.; Hendricks, T.; Johnson, V.; Kelly, K.; Kramer, B.; O’Keefe, M.; Sprik, S.; Wipke, K. ADVISOR: A systems analysis tool for advanced vehicle modeling. J. Power Sources 2002, 110, 255-266. [CrossRef]

56. Zhou, M.; Jin, H. Development of a transient fuel consumption model. Transp. Res. Part D Transp. Environ. 2017, 51, 82-93. [CrossRef]

57. Zhang, Y.T.; Claudel, C.G.; Hu, M.B.; Yu, Y.H.; Shi, C.L. Develop of a fuel consumption model for hybrid vehicles. Energy Convers. Manag. 2020, 207, 112546. [CrossRef] 
58. Guang, H.; Jin, H. Fuel consumption model optimization based on transient correction. Energy 2019, 169, 508-514. [CrossRef]

59. Lindgren, M. A transient fuel consumption model for non-road mobile machinery. Biosyst. Eng. 2005, 91, 139-147. [CrossRef]

60. Zhang, L. Investigation of Performance Deterioration and Control Strategy of Automotive Diesel Engine Under Transient Operation Conditions; Jilin University: Changchun, China, 2015.

61. Zhang, B.D.; Zhang, X.; Zhang, L.; Xi, L.H. Development and validation of a series hybrid electric bulldozer model on whole working condition. Key Eng. Mater. 2016, 693, 1811-1817. [CrossRef]

C 2020 by the authors. Licensee MDPI, Basel, Switzerland. This article is an open access article distributed under the terms and conditions of the Creative Commons Attribution (CC BY) license (http://creativecommons.org/licenses/by/4.0/). 